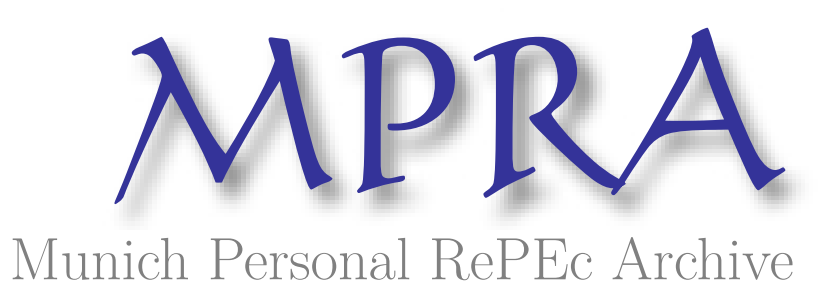

\title{
Financial Experts, Asset Prices and Reputation
}

Rudiger, Jesper and Vigier, Adrien

European University Institute, University of Oslo

28 November 2013

Online at https://mpra.ub.uni-muenchen.de/51784/

MPRA Paper No. 51784, posted 10 Jan 2014 09:48 UTC 


\title{
Financial Experts, Asset Prices And REPUTATION*
}

\author{
Jesper Rudiger ${ }^{\dagger}$ and Adrien Vigier $^{\ddagger}$ \\ Job Market Paper
}

\begin{abstract}
We analyze how financial experts influence asset prices in a sequential trading model. In the model, an expert of unknown ability sends a report about asset values to traders, who then observe a signal about the expert's type. All information about the expert's ability is private to traders and only revealed through trades. When the expert's reputation is sufficiently high, traders ignore their private signal about ability and the market enters a reputational cascade in which no information about the expert reaches the market. Reputational cascades are conducive to asset price bubbles, which eventually result in market crashes when cascades terminate. Rather than being caused by the release of new information, market crashes in our model result from the sudden depreciation of past accumulated information. Finally, we show that reputational cascades are bad for liquidity and induce high price volatility.
\end{abstract}

Keywords: Informational Cascades; Experts; Reputation; Asset Price Bubbles JEL Codes: D82; D83; D84; G14; G20

\footnotetext{
*The authors would like to thank Antonio Cabrales, Piero Gottardi, David Levine, Andrea Mattozzi, Marco Ottaviani, Thomas Palfrey, Peter Sørensen and Pierre-Olivier Weill for helpful conversations, as well as seminar audiences at the European University Institute and the Free University Amsterdam. All mistakes are our own.

${ }^{\dagger}$ Department of Economics, European University Institute, Via delle Fontanelle 10, I-50014 San Domenico, Italy. Telephone: +39 0554685 698. E-mail: jesper.rudiger@eui.eu (corresponding author)

$\ddagger$ Department of Economics, University of Oslo, Moltke Moes Vei 31, N-0851 Oslo, Norway. Telephone: +47 2285 4520. E-mail: a.h.vigier@econ.uio.no
} 


\section{Introduction}

Models of asset pricing traditionally assume that traders' information about assets is exogenous, yet financial news is often provided by experts of unknown ability who may act strategically. Large investment banks, for instance, provide advice to clients in the form of reports about firms, stocks, and other economic variables. Market participants must therefore simultaneously incorporate expert advice and evaluate its reliability. This creates an endogeneity problem: the stronger the influence of the expert on the market, the harder it becomes to back out information about his ability.

The 2008 financial crisis put a spotlight on the role played by financial experts in determining asset prices. Some of the most respected financial institutions were at the forefront of backing assets that later turned out to be almost worthless. Regulators subsequently found conflicts of interest and occasionally outright incompetence to be at fault for this failure. This begs the following questions. If as it seems the experts were so wrong, how could they maintain their reputation for so long? And why did traders not use their private information to trade against bad expert recommendations? In retrospect, it seems that the status achieved by some pundits prior to the crisis effectively turned their predictions into self-fulfilling prophecies, and disabled the market's ability to evaluate their true ability.

This paper builds a model of an asset market with financial advice, and analyzes the role played by experts in market fluctuations. In particular, we study a sequential trading model in the spirit of Glosten and Milgrom (1985), but replace the exogenous information of traders by the report of an expert who may or may not be informed about the asset value. Traders observe a private signal about expert ability. We then show that when the expert's reputation is sufficiently high, traders ignore their private signal and trade based only on reports. Price movements thus become uninformative about expert ability. We refer to this kind of market behavior as a reputational cascade. Although in a reputational cascade the market no longer updates beliefs about ability, it still incorporates the expert's advice into prices. Thus, if he is of low ability, the market will go on absorbing the bad information provided by him.

The details of the model are as follows. Each period, one unit of a risky asset of unknown fundamental value is traded. Information about the asset value is provided by a single longlived expert of unknown ability, in the form of cheap talk reports communicated to traders. An expert of high ability sometimes observes a noisy signal about the asset value, and truthfully reports the information he possesses. An expert of low ability, on the other hand, knows 
nothing about the asset value and acts strategically to maximize reputation. To this end, he publishes reports, even though he has no information. At the beginning of each period, a market maker sets prices competitively and a single trader arrives. There are two types of traders. Liquidity traders trade for exogenous reasons. ${ }^{1}$ Informed traders are risk-neutral profit maximizers. They privately observe the expert's report and, when reading the report, obtain a noisy signal of the expert's ability. After one period, the report becomes public information, ${ }^{2}$ but a trader's information regarding expert ability remains private information and thus can only be revealed through his action.

Our model's flow of information is two-dimensional: information about the asset on the one hand, and information about the expert on the other. When there is a clash between the information in these two dimensions, traders are faced with a dilemma. A trader may for instance observe a positive report about the asset value from the expert, but at the same time receive a negative signal concerning expert ability. In this example, the report suggests that the asset may currently be undervalued, while the trader's signal suggests that it is in fact overvalued. When such dilemmas occur the trader's decision of whether to buy, sell or abstain depends in general on the entire history. However, we show that if (i) expert reputation is high and (ii) reports are sufficiently informative at the margin ${ }^{3}$ then, in equilibrium, traders ignore the private signals they observe and blindly follow the reports they receive. In this case, traders' actions no longer reveal information about expert ability, and the market enters a reputational cascade. Thus, while price adjustments prevent complete informational cascades from occurring (Avery and Zemsky, 1998) our results establish that partial informational cascades - whereby one entire dimension of the information flow altogether stops reaching the market - do occur.

Reputational cascades are instrumental to understanding the role played by experts in asset price bubbles. As long as the market is informative about the expert's ability, then price deviations from long-run levels are impeded on two fronts. (i) A low-ability expert's

\footnotetext{
${ }^{1}$ Liquidity (noise) traders assure the existence of a market price, by absorbing the losses made by the market maker on informed traders. They need not be irrational, but trade for reasons that are not informational.

${ }^{2}$ The assumption that the report becomes public information after one period can be relaxed, but is in line with actual practices. Goldman Sachs, for instance, offers exclusive advice to its client investors, but their recommendations eventually filter through to the public, either directly through public newsletters or indirectly through blogs. E.g. http://www.businessinsider.com/goldman-buy-large-banks-2012-12. The key assumption of our model lies in the fact that traders become informed of the report before the MM. Appendix B explores the microfoundations of this assumption.

${ }^{3}$ Marginal informativeness refers to the ability of a single report to move the asset valuation, holding expert reputation constant.
} 
reputation will on average decrease, limiting his impact on prices. (ii) A low-ability expert exposes himself by publishing reports, and will therefore avoid releasing (false) information. In a cascade, these two arguments no longer hold, and a low-ability expert inevitably exerts greater influence on prices. First, his predictions become self-fulfilling prophecies. Second, since he no longer fears revealing his type by publishing reports, the rate at which he releases information increases.

When the market is in a cascade, it stops accumulating information about the expert, but goes on accumulating information about the asset. Thus, while the expert's reputation is constant, the marginal informativeness of his reports is not. If asset fundamentals are not too volatile, the marginal informativeness of an extra report will vanish and, in particular, will eventually fall below the threshold needed to sustain the cascade. A crash occurs when the market exits a reputational cascade driven by a low-ability expert. At this point, the market starts losing faith in the ability of the expert, and prices dive. This mechanism contrasts with usual arguments. Rather than being caused by the release of new information, the crash results from the depreciation of past accumulated information. ${ }^{4}$

Finally, we compare market behavior in a cascade economy with that of a fictional economy in which cascades never occur. We find that the cascade economy is less liquid, in that it has a higher bid-ask spread, than the no-cascade economy. The reason is that the activity of informed traders increases in a cascade, causing losses to the market maker. ${ }^{5}$ The market maker's equilibrium response is to increase the bid-ask spread to cover the losses with gains from dealing with liquidity traders. Increased informed trader activity also leads to higher trade frequency. These two results in conjunction imply that the cascade economy has higher price volatility than the no-cascade economy.

After the literature review, the paper proceeds as follows. Section 2 describes a model of a financial market with advice. Section 3 analyzes the incentives of traders and experts, as well as the price setting in this market. Section 4 contains the main results on the existence of cascades. Section 5 applies the previous findings to analyze asset price bubbles and crashes. Section 6 presents comparative statics illustrating the effect of cascades on liquidity and price volatility. Section 7 concludes. Appendix A contains auxiliary results on trader behavior. Appendix B demonstrates that our results depend on information asymmetry between traders

\footnotetext{
${ }^{4}$ See section 5.2 for an overview of the related literature on asset price bubbles.

${ }^{5}$ Since the informed traders have better information than the market maker, he must on average lose when he trades with them, due to adverse selection.
} 
and market makers, and builds micro-foundations that explain the asymmetry. All proofs are contained in Appendix C.

\section{$1.1 \quad$ Related Literature}

The present paper is to the best of our knowledge the first to examine asset markets' failure to efficiently evaluate the ability of financial experts.

Our paper is first and foremost related to the by now classic literature on asset price formation (Grossman, 1976; Grossman and Stiglitz, 1980; Glosten and Milgrom, 1985; Kyle, 1985), and in particular to the subsequent analysis of herding and informational cascades in asset markets (Avery and Zemsky, 1998; Dasgupta and Prat, 2008; Park and Sabourian, 2011). As in Avery and Zemsky, multidimensional uncertainty plays an important role in our paper. However, all the aforementioned papers assume exogenously informed traders, whereas we examine the role of financial experts. Thus, unlike them, our model incorporates uncertainty about the precision of information which stems from uncertainty about expert ability. Moreover, while our reputational cascades constitute a form of informational cascades, informed traders do not "herd" in a reputational cascade. They buy following a positive report, and sell following a negative one. If their behavior is akin to herding, it is in the sense that they blindly follow the expert's advice once they observe that enough traders have done so before them.

The role of financial experts in the procurement of information was first examined by Admati and Pfleiderer (1986) and later by Benabou and Laroque (1992). Admati and Pfleiderer examine optimal disclosure of information for a profit maximizing financial expert and shows that, typically, this entails adding noise to the information that the expert actually has in order to overcome the dilution in the value of information due to its leakage through informative prices. But, in line with earlier papers, there is no uncertainty in equilibrium about the quality of the information provided by the expert. In this sense, our paper is possibly closer to Benabou and Laroque. The authors analyze the credibility of a financial expert with short-run incentives to deceive the market and resort to insider trading. ${ }^{6}$ While Benabou and Laroque study a financial expert who cares about reputation, their expert - unlike ours - is of known ability (but unknown honesty). Furthermore, prices play no role in evaluating the expert. Ottaviani and Sørensen (2006c) is in parts related to us. In their paper profesional

\footnotetext{
${ }^{6}$ In a similar vein, Allen and Gale (1992) investigate how an uninformed manipulator can make a profit on the stock market by pretending to be an informed trader.
} 
forecasters endeavor, through their forecasts of a stock price, to convince the market that they are well informed. If the forecasts affect the price, a "beauty contest" among forecasters emerges. However, whereas Ottaviani and Sørensen investigate a one-shot game in which the market always learns about forecasters' ability, our focus is on dynamic revelation of information about expert ability, and the ultimate failure of the market to properly channel this information. ${ }^{7}$

In Section 5.2 we discuss how our work relates to the literature on asset price bubbles.

\section{A Model of a Financial Market with Advice}

We consider a discrete-time sequential trade market for financial assets in the spirit of Glosten and Milgrom (1985), and introduce a strategic expert who is the sole source of information about the asset value.

The Asset. We examine an asset whose fundamental value is unknown and follows the stochastic process $\left\{\theta_{t}\right\}_{t=1}^{\infty}$, where $\theta_{t} \in\{-1,1\}$ and $\mathbb{E}\left(\theta_{t}\right)=0$ for all $t$. We impose no further restriction on the stochastic process, except that it is common knowledge among all market participants. $^{8}$

The Market Maker. Prices are set by a market maker (MM) who interacts with an infinite sequence of individuals chosen from a continuum of traders. Each trader has the option to buy or sell one unit of the asset, or to abstain from trading. The sequence of traders is indexed by $t$, and $y_{t} \in\{a, b, n\}$ denotes the action of the trader in that period: $y_{t}=a$ if he buys, $y_{t}=b$ if he sells, and $y_{t}=n$ if he abstains. The MM posts ask $\left(p_{t}^{a}\right)$ and bid $\left(p_{t}^{b}\right)$ prices at which he will sell or buy one unit of the asset, respectively. The MM is risk-neutral and competitive, and quoted prices thus equal the expected asset value conditional on (a) all publicly available information at the beginning of period $t$ (i.e. before trade takes place), denoted $\mathcal{H}_{t}$, and (b) the current order of trade. Let $\mathbb{E}_{t}(\cdot)=\mathbb{E}\left(\cdot \mid \mathcal{H}_{t}\right)$. Hence $p_{t}^{a}=\mathbb{E}_{t}\left(\theta_{t} \mid y_{t}=a\right)$

\footnotetext{
${ }^{7}$ More generally, we are connected to the broader reputational cheap talk literature (Scharfstein and Stein, 1990; Trueman, 1994; Zwiebel, 1998; Ottaviani and Sørensen, 2006a,b), which does not analyze asset markets. They find that experts tend to bias reports toward priors and that multiple experts tend to herd.

${ }^{8}$ One possibility is to think of the asset as a "growth stock" that currently pays no dividends, but which is expected in the future to yield a stochastic payoff $V$. $\theta_{t}$ is then the expectation of $V$, conditional on all period $t$ information. Players try to learn $\theta_{t}$, since this is the best estimate of the value of the stock.
} 
and $p_{t}^{b}=\mathbb{E}_{t}\left(\theta_{t} \mid y_{t}=b\right)$. We let $p_{t}^{0}=\mathbb{E}_{t}\left(\theta_{t}\right)$ denote the public valuation of the asset at the beginning of period $t$, which we sometimes refer to as the "price" for simplicity.

The Expert. There is a single financial expert (FE) who remains the same throughout the game, and has ability type $\tau \in\{B, G\}$ which is drawn at the beginning of the game, and is known only to him. With probability $1-\lambda_{0}$ he is $\operatorname{bad}(\tau=B)$ and knows nothing about the asset. On the other hand, with probability $\lambda_{0}$ the FE is $\operatorname{good}(\tau=G)$, and possesses valuable information: at the beginning of period $t$ he observes, with probability $1 / 2$, the private signal $x_{t} \in\{-1,1\}$ such that

$$
\mathbb{P}\left(x_{t}=\theta_{t}\right)=\phi \in(1 / 2,1) .
$$

We let $x_{t}=0$ if no signal is observed in period $t$. Each period, and before trade takes place, the FE chooses whether or not to publish a cheap talk report $r_{t} \in\{-1,1\}$. We let $r_{t}=0$ if the $\mathrm{FE}$ does not publish a report in period $t$.

Before trade, the expert's report is observed by traders alone. This informational advantage conferred upon traders is crucial to the analysis of our paper. ${ }^{9}$ To simplify the analysis, we further assume that the expert's report eventually filters through and become public knowledge after one period. ${ }^{10}$ Let $\mathcal{R}_{t}=\left(r_{0}, \ldots, r_{t}\right)$ denote the sequence of reports and $\mathcal{Y}_{t}=\left(y_{0}, \ldots, y_{t}\right)$ the sequence of trades up to and including period $t$. The public information at the beginning of a period thus consists of previous reports as well as the trading history:

$$
\mathcal{H}_{t}=\left\{\mathcal{R}_{t-1}, \mathcal{Y}_{t-1}\right\}
$$

Traders. There are two broad classes of traders. Informed traders gather information from the FE and maximize expected profit at the market maker's expense, while liquidity traders act for exogenous motives and without regard for expected profit. Let $\mu>0$ be the probability of an informed trader arriving in any given period, and assume that liquidity traders buy or sell the asset with equal probability. ${ }^{11}$

While traders do not hold any direct private information concerning the asset, reading

\footnotetext{
${ }^{9}$ Appendix B first examines the implication of dropping this assumption, and later explores its microfoundations. In particular, we show that it can be supported for some intermediate cost of acquiring information early.

${ }^{10}$ See also further discussion of this simplifying assumption in the introduction.

${ }^{11}$ The latter assumption is for expositional convenience. We only need $\mu>0$ together with the liquidity traders' willingness to trade at any price to assure the existence of a market price, despite the information asymmetry.
} 
reports (imperfectly) informs them of the expert's type via the private signal $s_{t} \in\{0,1\}$. For instance, the expert may in his reports reveal some information regarding his assessment of other auxiliary economic variables which traders know something about, and which they can then use to make inferences about the expert's type. No report implies no signal, so that $s_{t}=0$ if $r_{t}=0 .{ }^{12}$ When a bad expert publishes a report, he always generates the signal $s_{t}=0$, i.e. $\mathbb{P}\left(s_{t}=1 \mid \tau=B\right)=0$. On the other hand

$$
\mathbb{P}\left(s_{t}=1 \mid \tau=G, r_{t} \neq 0\right)=\pi,
$$

where $\pi \in(0,1)$. Observing $s_{t}=1$ is thus hard evidence that $\tau=G$. Let $\mathbb{P}_{t}(\cdot)=\mathbb{P}\left(\cdot \mid \mathcal{H}_{t}\right)$. The trader's belief about the expert's type, based on his private information, is then $\beta_{t}=$ $\mathbb{P}_{t}\left(\tau=G \mid r_{t}, s_{t}\right)$.

Finally, let $\underline{\xi}_{t}$ denote an informed trader's strategy in period $t$. This is a vector with elements $\xi_{t}^{y_{t}}\left(r_{t}, s_{t}\right)$ that specify the probability with which he takes action $y_{t}$ conditional on information set $\left(r_{t}, s_{t}\right)$ and $\sum_{y_{t}} \xi_{t}^{y_{t}}\left(r_{t}, s_{t}\right)=1$.

Reputation. Each period, the market updates beliefs regarding the expert's ability $\tau$ using all publicly available information. We let $\lambda_{t}=\mathbb{P}_{t}(\tau=G)$ denote the reputation of the $\mathrm{FE}$ at the beginning of period $t$. The good expert is a behavior type, and in particular we assume that he is truthful and always reports his own signal: $r_{t}=x_{t}$ for all $t$. The bad expert, on the other hand, is risk neutral and cares to maximize his reputation. We assume, in the interest of tractability, that he is myopic in the sense that each period he chooses his strategy so as to maximize next period's (expected) reputation.

Let $q_{t}^{+}$(resp. $q_{t}^{-}$) denote the probability, conditional on $\mathcal{H}_{t}$, that a good expert receives a positive signal (resp. negative signal) in period $t .{ }^{13}$ Similarly, let $\underline{\sigma}_{t}=\left(\sigma_{t}^{+}, \sigma_{t}^{-}\right)$denote the reporting strategy of a bad expert in period $t$, where $\sigma_{t}^{+}$(resp. $\sigma_{t}^{-}$) indicates the probability of a positive report (resp. negative report).

The Game. Within a given period, the FE first publishes his report which is read only by the trader, the MM then announces a bid and an ask price, and finally the trader makes his order to the MM. A good expert is always truthful, $r_{t}=x_{t}$, whereas a bad expert is strategic. An equilibrium is a vector of prices, strategies and beliefs $\left(\underline{p}_{t}, \underline{\xi}_{t}, \underline{\sigma}_{t}, \lambda_{t}, \beta_{t}\right)$, such that the agents

\footnotetext{
${ }^{12}$ I.e. no report implies no signal beyond the fact that no report was sent, which itself may be informative. ${ }^{13}$ Thus, $q_{t}^{+}=\mathbb{P}_{t}\left(x_{t}=1 \mid \tau=G\right)$ and $q_{t}^{-}=\mathbb{P}_{t}\left(x_{t}=-1 \mid \tau=G\right)$.
} 
maximize payoffs and beliefs are derived using Bayes' Rule, whenever possible. ${ }^{14}$

\section{Preliminary Analysis}

We explore in this section the detailed workings of the market. Our aim is to shed some light on agents' behavior and the formation of prices. The expert moves first and decides which report to send with what probability. In doing so, he affects informed traders' valuations. Traders' actions and bid/ask prices are then jointly determined. Prices thus reflect the information of all active traders: informed traders on the one hand and liquidity traders on the other. Section 3.1 is devoted to the study of the expert. We analyze his incentives to distort information if he is bad, and explore in particular how the behavior of a bad expert generally differs from that of a good one. We then examine in section 3.2 the behavior of traders and the formation of prices.

\subsection{Reporting Strategies}

A low-ability expert faces the following trade-off. If he releases a report, he faces the risk that the action of an informed trader may reveal information about his true type. On the flip side, the action of a liquidity trader may corroborate his report and thereby boost his reputation. If he chooses instead not to release a report, he avoids the risk of revealing more information about his type - over and above the fact that he chose not to release a report. But if a bad expert is more likely than a good one not to release a report, he will lose reputation for sure. In equilibrium, his strategy will balance these two motives.

Reputation is updated using all publicly available information - consisting of the history of reports and trades. We can express next period's reputation as a function of $\left(r_{t}, y_{t}\right)$ as follows

$$
\lambda_{t+1}\left(r_{t}, y_{t}\right)=\frac{\lambda_{t} q_{t}^{r_{t}} \mathbb{P}_{t}\left(y_{t} \mid r_{t}, G\right)}{\lambda_{t} q_{t}^{r_{t}} \mathbb{P}_{t}\left(y_{t} \mid r_{t}, G\right)+\left(1-\lambda_{t}\right) \sigma_{t}^{r_{t}} \mathbb{P}_{t}\left(y_{t} \mid r_{t}, B\right)}
$$

Notice here that $y_{t}$ only imperfectly reveals $s_{t}$. This is due to the presence of liquidity traders, but is further aggravated whenever informed traders do not reveal their private information through trades.

\footnotetext{
${ }^{14}$ Payoff maximization implies that at all $t$, (i) the prices $\underline{p}_{t}$ yield zero expected profits to the MM, conditional on $\left(\underline{\xi}_{t}, \underline{\sigma}_{t}, \lambda_{t}\right)$; (ii) the bad expert's strategy $\underline{\sigma}_{t}$ maximizes $\mathbb{E}_{t}\left(\lambda_{t+1} \mid \underline{\xi}_{t}, \underline{\sigma}_{t}\right)$; and (iii) the trader's strategy $\underline{\xi}_{t}$ maximizes expected profits conditional on $\left(\underline{p}_{t}, \underline{\sigma}_{t}, \beta_{t}\right)$.
} 
By publishing report $r_{t}$, the expert induces a distribution $\underline{\delta}_{t}\left(r_{t}, \tau\right)$ over trading outcomes. ${ }^{15}$ Let $\lambda_{t+1}^{e}\left(r_{t}\right)=\mathbb{E}_{\underline{\delta}_{t}\left(r_{t}, B\right)}\left(\lambda_{t+1}\left(r_{t}, y_{t}\right)\right)$. This denotes the reputation which a bad expert expects to have next period if he publishes $r_{t}$ now. It is straightforward to see that any equilibrium must induce a mixed strategy on the part of a bad FE. In particular, the following equilibrium condition must hold:

$$
\lambda_{t+1}^{e}(1)=\lambda_{t+1}^{e}(0)=\lambda_{t+1}^{e}(-1) .
$$

The realized market price (which reflects the trading outcome) is the only channel through which reputation is updated, and therefore the expert chooses his report so as to generate the distribution of prices that is most favorable to his reputation. The obvious difficulty to efficiently evaluate experts in such an environment provides important leverage to experts of low ability. The following lemma examines the resulting behavior on the part of low ability experts. We let $\underline{\sigma}_{t}\left(\underline{\xi}_{t}\right)$ denote the strategy solving (2), i.e. a bad expert's best response to traders playing $\underline{\xi}_{t}$. Moreover, we define an expert's aggressiveness in period $t$ as the probability with which he publishes a report in that period. For a good expert, this is $q_{t}=q_{t}^{+}+q_{t}^{-}$. For a bad expert, it is $\sigma_{t}=\sigma_{t}^{+}+\sigma_{t}^{-}$.

Lemma 1. $\underline{\sigma}_{t}\left(\underline{\xi}_{t}\right)$ is uniquely determined. Moreover:

1. If $\underline{\xi}_{t}^{y_{t}}\left(r_{t}, 1\right)=\underline{\xi}_{t}^{y_{t}}\left(r_{t}, 0\right)$ for all $\left(y_{t}, r_{t}\right)$, then $\underline{\sigma}_{t}\left(\underline{\xi}_{t}\right)=\underline{q}_{t}$.

2. If $\underline{\xi}_{t}^{y_{t}}\left(r_{t}, 1\right) \neq \underline{\xi}_{t}^{y_{t}}\left(r_{t}, 0\right)$ for some $\left(y_{t}, r_{t}\right)$, then $\sigma_{t}\left(\underline{\xi}_{t}\right)<q_{t}$.

Part 1 says that when the distribution over actions is the same regardless of the expert's type, then the best thing a bad expert can do is to replicate the frequencies with which a good expert publishes different reports. Part 2 states that when the distribution over actions is affected by expert type, then a bad expert is strictly less aggressive than a good one. As discussed above, publishing a report is risky, in that it releases information about the expert's type to the traders.

\subsection{Price Formation}

This section takes the expert's strategy as given, and analyzes price setting and traders' behavior during period $t$. The information structure of our model decomposes asset prices into two components: the information accumulated in the reporting history and the reputation

\footnotetext{
${ }^{15}$ This distribution reflects both the presence of liquidity traders and informed traders: $\delta_{t}^{y_{t}}\left(r_{t}, \tau\right)=$ $\mathbb{P}_{t}\left(y_{t} \mid \tau, r_{t}\right)$.
} 
of the expert. The first component is identified by the valuation conditional on the expert being good, or simply the conditional valuation, which is given by

$$
\theta_{t}^{G}\left(\mathcal{R}_{t-1}\right)=\mathbb{E}\left(\theta_{t} \mid \mathcal{R}_{t-1}, \tau=G\right)
$$

Given that the reporting history is of no value if the expert is bad, valuations weigh the reporting history according to the best estimate of its reliability. We can thus compute the public valuation as

$$
p_{t}^{0}=\lambda_{t} \theta_{t}^{G}\left(\mathcal{R}_{t-1}\right)
$$

Valuations are simply the product of reputation and the conditional valuation.

Consider next an informed trader. He observes $\left(r_{t}, s_{t}\right)$, which allows him to update his belief about expert type to

$$
\beta_{t}\left(r_{t}, s_{t}\right)=\frac{\lambda_{t} q_{t}^{r_{t}} \mathbb{P}\left(s_{t} \mid r_{t}, G\right)}{\lambda_{t} q_{t}^{r_{t}} \mathbb{P}\left(s_{t} \mid r_{t}, G\right)+\left(1-\lambda_{t}\right) \sigma_{t}^{r_{t}} \mathbb{P}\left(s_{t} \mid r_{t}, B\right)}
$$

Since $s_{t}=1$ perfectly reveals that the FE is good, we obtain $\beta_{t}\left(r_{t}, 1\right)=1$. The private signal $s_{t}=0$ on the other hand induces the updated beliefs $\beta_{t}\left(r_{t}, 0\right)=\frac{\lambda_{t} q_{t}^{r_{t}}(1-\pi)}{\lambda_{t} q_{t}^{r_{t}}(1-\pi)+\left(1-\lambda_{t}\right) \sigma_{t}^{r_{t}}}$. In general, this can be greater or smaller than the public belief $\lambda_{t}$, since the report itself reveals information about the expert's type. But clearly, if $\sigma_{t}^{r_{t}} \geq q_{t}^{r_{t}}$ then $\beta_{t}\left(r_{t}, 0\right)<\lambda_{t}$, since in this case both the report and the signal are more likely to be observed if the expert is bad.

An informed trader's valuation of the asset, denoted $v_{t}\left(r_{t}, s_{t}\right)$, departs from (4) on two dimensions. First, his belief about the expert is updated according to $\beta_{t}\left(r_{t}, s_{t}\right)$. Second, the trader possesses the expert's latest report, $r_{t}$. We thus have

$$
v_{t}\left(r_{t}, s_{t}\right)=\beta_{t}\left(r_{t}, s_{t}\right) \theta_{t}^{G}\left(\mathcal{R}_{t-1}, r_{t}\right)
$$

Consider now the MM. He sets a price that reflects the information revealed by the trader's action, taking into account the possibility of uninformative liquidity trading. Let $Z$ denote the event that the trader is informed. For $y_{t} \in\{a, b\}$ we then obtain

$$
p_{t}^{y_{t}}=\mathbb{P}_{t}\left(Z \mid y_{t}\right) \sum_{r_{t}, s_{t}} \mathbb{P}_{t}\left(r_{t}, s_{t} \mid y_{t}, Z\right) v_{t}\left(r_{t}, s_{t}\right)+\left(1-\mathbb{P}_{t}\left(Z \mid y_{t}\right)\right) \lambda_{t} \theta_{t}^{G}\left(\mathcal{R}_{t-1}\right)
$$

With probability $\mathbb{P}_{t}\left(Z \mid y_{t}\right)$, the trader is informed and the market maker's valuation is the average of the valuation of informed traders taking action $y_{t}$. With probability $1-\mathbb{P}_{t}\left(Z \mid y_{t}\right)$ 
the MM faces a liquidity trader, in which case trade reveals no new information about the asset. $^{16}$

An informed trader buys if $v_{t}\left(r_{t}, s_{t}\right) \geq p_{t}^{a}$, sells if $v_{t}\left(r_{t}, s_{t}\right) \leq p_{t}^{b}$ and abstains otherwise. His action thus depends on his own valuation and the price chart, which reflects the public valuation and the information revealed by the trader's action. Notice that the asymmetry of information between informed traders and MM is three-fold. An informed trader knows the content of the latest report, his private signal of the expert's type, and the motives of his action. ${ }^{17}$ We show in Appendix A that, in general, it is impossible to order traders' valuations according to their information set $\left(r_{t}, s_{t}\right)$. This ordering is history dependent. However, for any history, prices are well-defined. Moreover, the ask price (respectively, bid price) is strictly larger (respectively, smaller) than the public valuation. ${ }^{18}$

Lemma 2. Prices are uniquely determined given $\underline{\sigma}_{t}$. Moreover, in equilibrium and when $\lambda_{t}>0$ then $p_{t}^{b}<p_{t}^{0}<p_{t}^{a}$.

\section{Reputational Cascades}

Our model departs from previous literature by the nature of its information flow to the various market participants and, ultimately, by the way in which prices eventually incorporate this information. Each period, information flows in the form of signal $x_{t}$ to the FE and signal $s_{t}$ to trader $t$. Our flow of information thus takes the following simple form: information about the asset value on the one hand (viz. $x_{t}$ ), and information about the reliability of this information on the other hand (viz. $s_{t}$ ). Given that good experts accurately report the signals they observe, some information contained in signal $x_{t}$ always reaches the market (Proposition 1), by construction. Price adjustments prevent complete informational cascades from ever occurring (Avery and Zemsky, 1998). Notwithstanding, we show that partial informational cascades - whereby one entire dimension of the informational flow (viz. $s_{t}$ ) altogether stops reaching the market - do occur in our model (Theorem 1). Our informational cascades are of the reputational kind: cascades prevent the efficient flow of information regarding expert type and, thereby, reputation to evolve normally. First, reflecting unresolved uncertainty about

\footnotetext{
${ }^{16}$ Note however that if the MM faces a liquidity trader his valuation of the asset differs from last period's price since in the meantime last period's report has become public information and public beliefs about expert type have been updated.

${ }^{17}$ I.e. he knows that he is an informed trader and not a liquidity trader.

${ }^{18} \mathrm{As}$ is standard in this type of models, the willingness of liquidity traders to absorb loses implies that the market does not break down, despite the obvious adverse selection problem.
} 
reliability of past information, cascades thus prevent prices from converging to the true asset value. Second, and perhaps more worryingly, cascades induce self-fulfilling prophecies whereby - among others - a bad expert's forecasts always hit target.

The concept of an informational cascade is straightforward. When the market is in an informational cascade, no new information about the asset reaches the market. Prices therefore stop evolving. The following definition is adapted from Avery and Zemsky (1998).

Definition 1. A complete informational cascade, occurs in period $t$ when

$$
\mathbb{P}_{t}\left(y_{t}, r_{t} \mid \theta_{t}\right)=\mathbb{P}_{t}\left(y_{t}, r_{t}\right), \quad \forall r_{t}, y_{t}
$$

We begin this section with a simple result. Namely, given that the focus of our analysis is on truthful equilibria - whereby good experts accurately report the (informative) signals they observe - informational cascades never occur in the framework we explore.

Proposition 1. An informational cascade never occurs if $\lambda_{t}>0$.

The rest of this section aims to mitigate the view expressed in our first proposition, and show that while some information always reaches the market, other information is typically lost under way. The following definition extends the concept introduced in definition 1, and forms the basis of all subsequent results.

Definition 2. A reputational cascade occurs in period $t$ when

$$
\mathbb{P}_{t}\left(y_{t}, r_{t} \mid \tau\right)=\mathbb{P}_{t}\left(y_{t}, r_{t}\right), \quad \forall r_{t}, y_{t}
$$

In contrast to an informational cascade, the only information which in a reputational cascade does not reach the market is information about the expert. ${ }^{19}$ As the following lemma indicates, reputational cascades do however have important consequences. First, and evidently, they impede the normal evolution of expert reputation. Second, they induce self-fulfilling prophecies whereby - among others - bad expert forecasts always hit target.

Lemma 3. If the market is in a reputational cascade in period then

$$
\text { 1. } \mathbb{P}\left(\lambda_{t+1}=\lambda_{t}\right)=1 \text {. }
$$

\footnotetext{
${ }^{19}$ Of course, any complete informational cascade is in particular a reputational cascade.
} 


\section{An informed trader who observes $r_{t}=1$ buys the asset with probability 1 .}

3. An informed trader who observes $r_{t}=-1$ sells the asset with probability 1 .

While informational cascades never occur, we next show that reputational cascades are in principle possible. The intuition follows from two steps. First, as $\lambda_{t}$ approaches 1 the valuation of traders, $v_{t}\left(r_{t}, s_{t}\right)$, converges to the conditional valuation, $\theta_{t}^{G}\left(\mathcal{R}_{t-1}, r_{t}\right)$. Second, we can strictly order the conditional valuations and the prices: $\theta_{t}^{G}\left(\mathcal{R}_{t-1}, 1\right)>p_{t}^{a}>p_{t}^{b}>$ $\theta_{t}^{G}\left(\mathcal{R}_{t-1},-1\right)$ for all $\lambda_{t}$. Thus, as reputation increases toward one, traders begin to trade exclusively according to the report $r_{t}$ and, in particular, ignore any available information regarding expert type. As discussed earlier, we can view this as a conflict between two pieces of information. The trader has private information about the asset and about the expert. If at some point it is sufficiently likely that the expert is of high ability, then the information about the asset is always more valuable to the trader. Thus, even if a trader receives a bad signal about the expert's ability, he cannot afford to ignore the information contained in the expert's report.

The next proposition summarizes our findings: above a threshold reputation, informed traders start ignoring $s_{t}$ and the market enters a reputational cascade.

Proposition 2. There exists $\hat{\lambda}_{t} \in(0,1)$ such that if $\lambda_{t} \geq \hat{\lambda}_{t}$ then the the market is in a reputational cascade.

The result of Proposition 2 is founded upon the observation that higher reputation enhances the asymmetry of information between traders and MM and, therefore, raises the occurrence of profitable opportunities for trade. We next develop the following complementary insight: other things equal, higher marginal informativeness of reports enhances information asymmetry between traders and MM. Thus more informative reports enhance the gains from trade and tend to facilitate the occurrence of reputational cascades.

Define, whenever $\theta_{t}^{G}\left(\mathcal{R}_{t-1},-1\right) \geq 0$, the quantities ${ }^{20}$

$$
I_{t}^{+}=1-\frac{\theta_{t}^{G}\left(\mathcal{R}_{t-1}\right)}{\theta_{t}^{G}\left(\mathcal{R}_{t-1}, 1\right)}, \quad I_{t}^{-}=1-\frac{\theta_{t}^{G}\left(\mathcal{R}_{t-1},-1\right)}{\theta_{t}^{G}\left(\mathcal{R}_{t-1}\right)} .
$$

\footnotetext{
${ }^{20}$ By extension, whenever $\theta_{t}^{G}\left(\mathcal{R}_{t-1}, 1\right) \leq 0$ define $I_{t}^{+}=1-\frac{\theta_{t}^{G}\left(\mathcal{R}_{t-1}, 1\right)}{\theta_{t}^{G}\left(\mathcal{R}_{t-1}\right)}$ and $I_{t}^{-}=1-\frac{\theta_{t}^{G}\left(\mathcal{R}_{t-1}\right)}{\theta_{t}^{G}\left(\mathcal{R}_{t-1},-1\right)}$. When $\theta_{t}^{G}\left(\mathcal{R}_{t-1},-1\right)<0 \leq \theta_{t}^{G}\left(\mathcal{R}_{t-1}\right)$, then a natural measure is $I_{t}^{-}=1+\left|\theta_{t}^{G}\left(\mathcal{R}_{t-1},-1\right)\right| \cdot \theta_{t}^{G}\left(\mathcal{R}_{t-1}\right)>1$, whereas $I_{t}^{+}$is as in the text. The last case can be defined similarly.
} 
By construction, both quantities lie in $[0,1] . I_{t}^{+}$(respectively, $I_{t}^{-}$) measures the marginal informativeness of a positive report (respectively, negative report) given the sequence of previous reports $\mathcal{R}_{t-1}$. The greater $I_{t}^{+}$the more information a positive report in period $t$ brings to the table. The quantity $I_{t}=\min \left\{I_{t}^{+}, I_{t}^{-}\right\}$measures the minimum marginal informativeness of reports in period $t$, and $I=\inf _{t, \mathcal{R}_{t-1}}\left\{I_{t}^{+}, I_{t}^{-}\right\}$the minimum marginal informativeness of reports, given any possible history.

Proposition 3. Higher marginal informativeness of reports facilitates cascades:

$$
\frac{\hat{\lambda}_{t}}{d I_{t}} \leq 0 \quad \text { and } \quad \lim _{I_{t} \rightarrow 0} \hat{\lambda}_{t}=1
$$

We can now state the paper's main result. The market either starts in a cascade or it does not. If it does not, bad experts will nevertheless on occasions publish reports. Doing otherwise would arise suspicion. With positive probability, exogenous shock to prices (liquidity traders) corroborate reports and, thereby, help improve the reputation of the expert. For sufficiently high reputation, the market enters a cascade. At this point the market stops gathering information concerning the expert, but goes on accumulating information about the assets. If the marginal informativeness of reports is bounded away from zero, then the market remains in a cascade permanently. Otherwise the marginal informativeness of reports eventually vanishes, as does with it the relative advantage of observing reports early. Gains from trade diminish, and the market exits the cascade it was in. The process described here then repeats itself.

Theorem 1. There exists $\hat{\mu}<1$ such that if $\mu \geq \hat{\mu}$ then a reputational cascade occurs with positive probability, independently of expert type (Good or Bad). However, if $I=0$, then a cascade ends in finite time almost surely.

When the mass of informed traders is large, trades naturally tend to be attributed to them. To the extent that informed traders respond to the signal $s_{t}$, trading patterns thus tend to induce large shifts in reputation. The object of the first part of the theorem is to show that, under such circumstances, the occasional occurrence of liquidity traders can alone drive the expert's reputation above the threshold of Proposition 2 - and hence trigger a reputational cascade. $^{21}$ Notice that liquidity traders thus play a dual role in our model. First, they prevent

\footnotetext{
${ }^{21}$ When there are few informed traders, actions will more often be attributed to liquidity trading, and even if the expert is lucky, his reputation will only move toward the threshold in small increments. As we approach the threshold, bad experts start behaving more like good ones, and traders become less responsive to $s_{t}$. Reputational adjustments thus decrease progressively. We have been unable to show whether or not this slowdown is sufficient to maintain the market below the threshold of Proposition 2.
} 
the breakdown of the market. Second, they are instrumental in the build-up of reputational cascades.

The second part of the theorem follows from Proposition 3. If $I=0$ then, as reports accumulate and marginal informativeness falls, the threshold reputation needed to sustain a cascade increases. Since reputation in a cascade is fixed, the market must first exit the cascade it is in before it (possibly) re-enters a cascade again.

The minimum informativeness of reports $(I)$ is intuitively linked to the volatility of the fundamental asset value. High volatility evidently sustains informativeness, since past information in this case rapidly loses relevance. By contrast, when the fundamental value is fixed, a good expert (and indeed a bad expert mimicking his behavior) eventually produces overwhelming evidence of one of the two states. The marginal informativeness of reports therefore disappears in the limit. It is for instance easy to show that if fundamentals are independent across time periods then $I=1$. By contrast, if the fundamental value is fixed, so that $\theta_{t+1}=\theta_{t}$ for all $t$, then $I=0$. By Theorem 1 , volatility therefore induces durable cascades. We show in the next section that the absence of volatility is on the other hand conducive to market crashes.

\section{Application: Bubbles and Crashes}

The short-lived bubble of the NASDAQ during the late 1990s provides the stereotypical example of the kind of episodes which our paper aims to contribute to explain. As shown in Figure 1 prices first rose steadily over the period 1994-1999, at a rate comparable to the average of the whole series. A period of frenzy began in January of 1999, in which the rate of growth suddenly accelerated. Quoting one observer, "Buzzwords like networking, new paradigm, information technologies, internet, consumer-driven navigation, tailored web experience, and many more examples of empty double-speak filled the media. [...] Investors started blindly grabbing every new issue without even looking at a business plan to find out, for example, how long the company would take before making a profit, if ever." ${ }^{22}$ The market crashed on March 11, 2000, eventually losing $78 \%$ of its value.

First, our model explains episodes of frenzies, in which prices start evolving rapidly in one direction. We show that when the market enters a reputational cascade (i) trading frequency suddenly augments and (ii) price paths start following past trends. Second, our model sheds

\footnotetext{
${ }^{22}$ Andrew Beattie on the DotCom crash. Source: http://www.investopedia.com/features/crashes/ crashes8.asp
} 


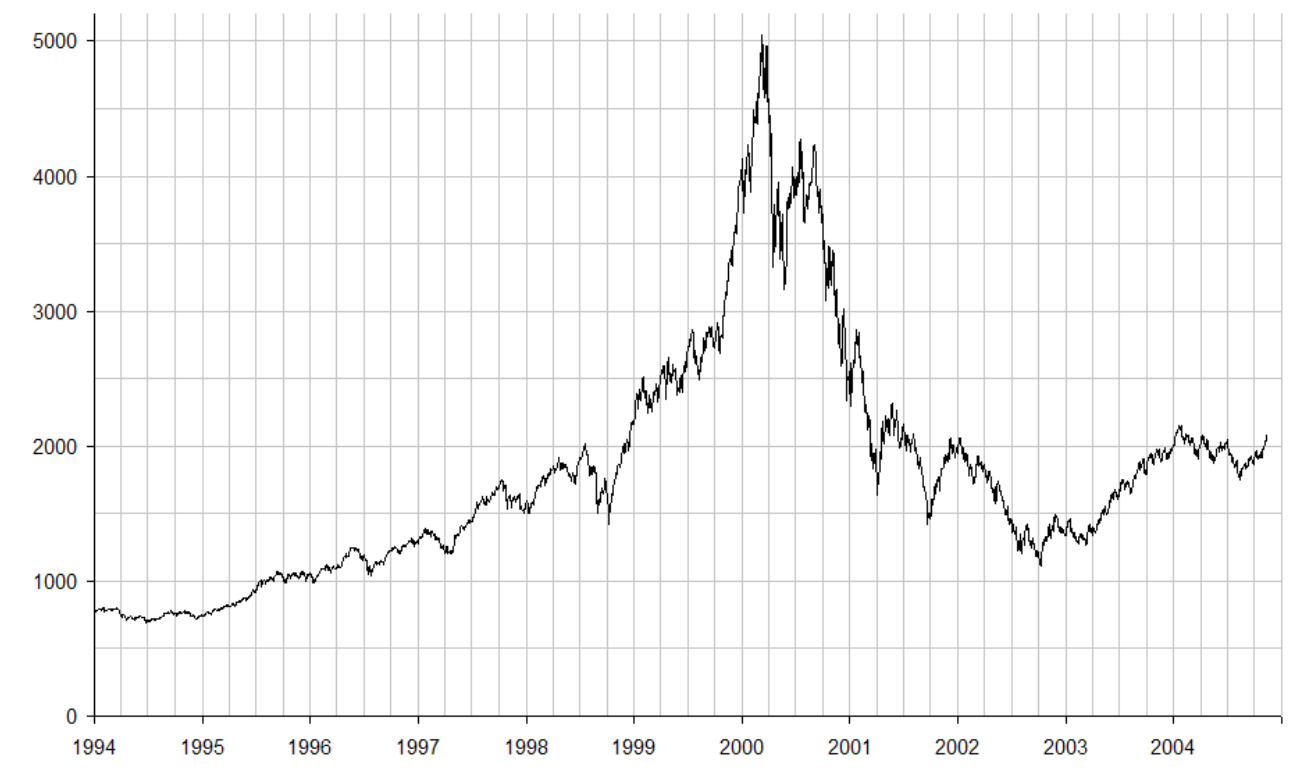

Figure 1: NASDAQ Closing Values, 1994 to 2008

light on crashes. The intuition is simple: when the market is in a reputational cascade, it stops accumulating information about the expert but goes on accumulating information about the asset; the stock of accumulated information then depreciates at once when eventually the market exits the cascade.

The following proposition is central to the analysis of this section. It follows directly from Lemmas 1 and 3, and is therefore stated without further proof.

Proposition 4. In equilibrium, when the market is in a reputational cascade, then $\underline{\sigma}_{t}=\underline{q}_{t}$ and, in particular, the bad expert is as aggressive as the good expert: $\sigma_{t}=q_{t}$. When the market is outside a reputational cascade, the bad expert is less aggressive than the good expert: $\sigma_{t}<q_{t}$.

It is worth repeating the intuition here. Outside a cascade, publishing a report is risky for a bad expert since doing so he releases information about his type to traders, while traders' actions may reveal this information. This induces a bad expert to publish reports less often than a good expert would. In a cascade, publishing a report is on the other hand risk-less to a bad expert, who therefore replicates the behavior of a good expert. In particular, he starts publishing reports more often. 
Section 5.1 contains our results. In section 5.2 we present a discussion and an overview of related literature on bubbles and crashes.

\subsection{Cascades, Bubbles and Crashes}

This section is organized around four simple results. Results 1 and 2 relate to the early frenzy phase. Results 3 and 4 explain the actual crash of the market. For clarity of exposition, we assume that the asset value is fixed. ${ }^{23}$

The frenzy phase of the market is first explained by the observation that the frequency of trade augments in a cascade. The intuition is as follows. According to Proposition 4, bad experts publish more aggressively in a cascade. Furthermore, when the market is in a cascade then, conditional on a report being published, an informed trader chooses to trade with probability 1 . These two observations lead to the following result:

Result 1. The frequency of trade augments in a cascade. If the market is in a cascade at time $t^{\star}$ and outside a cascade at time $t^{\dagger}$ then $\mathbb{P}_{t^{\star}}\left(y_{t^{\star}}=n\right)<\mathbb{P}_{t^{\dagger}}\left(y_{t^{\dagger}}=n\right)$.

Our second result records the following simple observations. If the market is in a cascade then prices track reports, going up following a positive report and going down following a negative one. But since bad experts strive to mimic good ones (Proposition 4), they tend to publish positive reports when prices are high and negative reports when prices are low. So in a cascade, prices follow past trends: moving upwards if prices are high and downwards if prices are low.

Result 2. In a cascade, prices follow past trends. If the market is in a cascade at time $t$ then letting $p_{t}$ denote the price at which trade takes place in period $t$ we have:

1. $\theta_{t}^{G}\left(\mathcal{R}_{t-1}\right)>0 \Rightarrow \mathbb{P}_{t}\left(p_{t}>p_{t-1}\right)>\mathbb{P}_{t}\left(p_{t}<p_{t-1}\right)$;

2. $\theta_{t}^{G}\left(\mathcal{R}_{t-1}\right)<0 \Rightarrow \mathbb{P}_{t}\left(p_{t}>p_{t-1}\right)<\mathbb{P}_{t}\left(p_{t}<p_{t-1}\right)$.

Results 1 and 2 together draw the contour of the frenzy phase of the market. The trading frequency is higher, and prices are likely to follow previous trends.

We now explore the workings of the crash phase. As indicated in (4), the prices of our model are made up of two terms. Reputation on the one hand, and conditional valuation

\footnotetext{
${ }^{23}$ I.e. $\theta_{t+1}=\theta_{t}$ with probability one.
} 
on the other. The following break-down of the period-to-period change in public valuation is instructive.

$$
p_{t+1}^{0}-p_{t}^{0}=\left[\lambda_{t+1}-\lambda_{t}\right] \theta_{t}^{G}\left(\mathcal{R}_{t-1}\right)+\lambda_{t+1}\left[\theta_{t+1}^{G}\left(\mathcal{R}_{t}\right)-\theta_{t}^{G}\left(\mathcal{R}_{t-1}\right)\right]
$$

The first term constitutes the price effect of a change in reputation. The second term embodies the marginal effect of an extra report. Changes to reputation affect the valuation of the entire reporting history, and therefore prices are more sensitive the greater the information accumulated in the reporting history. We henceforth refer to $\left|\theta_{t}^{G}\left(\mathcal{R}_{t-1}\right)\right|$ as the price sensitivity in period $t$. During a cascade, sensitivity builds up as reports accumulate. In particular, we have the following result.

Result 3. The sensitivity of prices is higher when the market exits a cascade than when it enters one. If the market enters a cascade a time $t^{\star}$ and exits the cascade at time $t^{\dagger}$ then $\left|\theta_{t^{\dagger}}^{G}\left(\mathcal{R}_{t^{\dagger}-1}\right)\right|>\left|\theta_{t^{\star}}^{G}\left(\mathcal{R}_{t^{\star}-1}\right)\right|$.

High price sensitivity makes the market vulnerable to sudden drops in reputation. According to Result 3, this is exactly the situation prevailing when the market exits a cascade.

Our final result provides the complementary insight explaining crashes: if the expert is bad, then at the time a cascade ends his reputation will on average fall. Effectively, at that point, the expert brings the market down with him.

Result 4. A bad expert's reputation on average decreases outside a cascade. If the market is outside a cascade at time $t$ then $\mathbb{E}_{t}\left(\lambda_{t+1} \mid \tau=B\right)<\lambda_{t}$.

Our results summarize as follows. Suppose the price is initially positive and that the expert is bad. When the market enters a cascade, a frenzy begins which is caused by increased access to information and higher willingness to act on this information. The price increases rapidly, until at some point the market exits the cascade. At that point, the price is more sensitive to changes in reputation. Since reputation on average goes down outside a cascade, a large fall of the price ensues.

\subsection{Discussion and Related Literature}

The previous section's results are founded upon (i) an informational friction - the imperfect observability of experts' type - and (ii) experts' strategic behavior. We first review related literature and then discuss our position relative to previous work. 
The literature on asset price bubbles and crashes can, roughly speaking, be divided into three strands of research. A first group of papers emphasizes the role of frictions in financial markets. While the nature of the frictions varies (capital constraints, transaction costs, regulatory constraints), all papers in this first group share the same flavor: some form of friction induces a lack of arbitrage. A second group of papers exploits distorted incentives among market participants. The idea is as follows: to the extent that market participants act upon motives unrelated to the long-term profitability of trades, prices will in general deviate from fundamentals. Finally, a third strand of research focuses on market manipulation. Here, one group of market participants strives to distort prices in order to take advantage of other market participants. ${ }^{24}$

Frictions: The early literature on speculation under rational expectations, such as for instance Tirole (1982), focused on frictions such as restricted short-selling as a source of inefficiency. However, most regulatory constraints concerning short-selling have disappeared during the extensive wave of reforms of the 1980s. In Shleifer and Vishny (1997), professional fund managers rely on client investors' capital in order to operate arbitrage. But arbitrage opportunities are founded upon long-term perspectives, while fund managers must report intermediate losses. Such intermediate losses are assumed to lead to less investment which is bad for fund managers, who may for that reason refrain from exploiting all arbitrage opportunities. In Lee (1998) transaction costs lead traders to accumulate information until a trigger occurs, at which point the sudden release of traders' information induces prices to re-adjust abruptly. Barlevy and Veronesi (2003) demonstrate that capital constraints can induce discontinuous price movements if some rational investors are informed about fundamentals while others are not. As prices decline, uninformed investors surmise that informed traders received negative information, which leads them to reduce their demand for assets. Capital constraints on the part of informed traders prevent these from absorbing assets' excess supply until prices drop lower yet.

Distorted incentives: The bulk of papers on distorted incentives examines the conspicuous agency problems found in financial markets. For instance, fund managers with limited liability maximize expected fees rather than expected profits, and may therefore forego arbitrage

\footnotetext{
${ }^{24}$ Important papers which do not fall within these categories include, among others, Zeira (1999), and Abreu and Brunnermeier (2003). In Zeira (1999) market crashes follow sudden and exogenous release of information. Abreu and Brunnermeier (2003) examine a setup in which traders become aware that assets are overvalued but attempt to ride the bubble to the last minute in order to maximize profits.
} 
opportunities (Allen and Gorton, 1993; Cuoco and Kaniel, 2011; Kaniel and Kondor, 2013). Similarly, fund managers with career concerns bias their choices towards a priori more likely actions in order to appear competent, possibly ignoring relevant information concerning fundamentals (Dasgupta and Prat, 2006, 2008; Dasgupta et al., 2011; Guerrieri and Kondor, 2012). The papers by Gennotte and Leland (1990) and Jacklin et al. (1992) on the other hand explore the destabilizing role played by deterministic trading strategies akin to portfolio insurance.

Market manipulation: In DeLong et al. (1990) the presence of momentum traders allows strategic traders to create and exploit short-term bubbles in the market. By contrast, in Benabou and Laroque (1992) one agent - the guru - plays a dual role. On the one hand, he informs other market participants. On the other hand, he trades the assets for which he supplies information. This dual role allows him to sell short assets whose prices he strategically boosts. In both papers, speculative behavior is purely destabilizing in the short run.

While our paper departs from all existing analyses, the views developed here provide complementary insights to those previously held. Within the aforementioned taxonomy our paper is, as indicated earlier, primarily related to the strand of research exploring frictions as a source of inefficiency. But whereas bubbles proceed from insufficient arbitrage in the bulk of papers considered, our bubbles are by contrast related to the occurrence of reputational cascades. Our emphasis on the procurement of information by financial experts and the agency problem which results, relates our paper to the second group of papers mentioned above. The manipulative behavior of bad experts attempting to influence prices in order to build a reputation relates our paper to the last strand of research discussed here.

\section{Liquidity and Price Volatility}

In this section we present and discuss some basic results on liquidity and price volatility. To assess the impact of reputational cascades, we follow Park and Sabourian (2011) in defining a hypothetical no-cascade economy, to contrast with the cascade economy we have analyzed until now. The two are identical, except that whenever the cascade economy is in a reputational cascade, then in the no-cascade economy: (i) only the trader with highest valuation buys, and (ii) only the trader with the lowest valuation sells. As shown in Appendix B, this would be the 
case if the reports were received simultaneously by the MM and the trader. ${ }^{25}$ To distinguish between the two cases we use a tilde to denote variables in the cascade economy, e.g. $\tilde{p}_{t}^{a}$, and a hat to denote variables in the no-cascade economy, e.g. $\hat{p}_{t}^{a}$.

We start by analyzing liquidity which, following the literature, we define as the inverse of the bid-ask spread. In a cascade, traders choose to trade with probability 1 . This worsens the adverse selection for the MM, and drives up the bid-ask spread necessary to avoid losses. We thus get the following result:

Result 5. Suppose the cascade and no-cascade economies are identical at the beginning of period $t$. The bid-ask spread is larger in the cascade economy than in the no-cascade economy:

$$
\tilde{p}_{t}^{a}-\tilde{p}_{t}^{b}>\hat{p}_{t}^{a}-\hat{p}_{t}^{b}
$$

Finally, we analyze price volatility. We define this by letting $p_{t}=p_{t}^{a}$ if the trader buys the asset, $p_{t}=p_{t}^{b}$ if he sells it, and $p_{t}=p_{t}^{n}=\mathbb{E}_{t}\left(\theta \mid y_{t}=n\right)$ if he abstains. ${ }^{26}$ We then define volatility as the variance of the price conditional on all available public information at the beginning of period $t: \mathbb{V}_{t}\left(p_{t}\right)=\mathbb{E}_{t}\left[\left(p_{t}-p_{t}^{0}\right)^{2}\right] \cdot{ }^{27}$ Combining results 1 and 5 allows us to show the following:

Result 6. Suppose the cascade and no-cascade economies are identical in at the beginning of period t. Price volatility is higher in the cascade economy than in the no-cascade economy:

$$
\mathbb{V}_{t}\left(\tilde{p}_{t}\right)>\mathbb{V}_{t}\left(\hat{p}_{t}\right)
$$

Result 6 is a simple consequence of trading occurring more often and with a larger price spread in the cascade economy than in the no-cascade economy. As we have shown, this is driven both by the desire of traders in a cascade to trade regardless of their private signal, and the increased aggressiveness of the bad expert.

This section therefore shows that reputational cascades have the "undesirable" properties that they make markets less liquid and prices more volatile.

\footnotetext{
${ }^{25}$ Notice, however, that the assumption we make here is not equivalent to the model explored in Appendix B. Here we fix trader behavior, but we still assume that the MM receives the report after trading has occurred. Changing this assumption would also affect price setting outside a cascade. Therefore, the hypothetical nocascade economy seems to be the most appropriate benchmark.

${ }^{26}$ The case of abstention can be seen as defining a price implicitly, in that information may be revealed by the decision not to trade.

${ }^{27}$ Notice that this definition of price volatility is within a given period, rather than between two periods. In general, we do not have $p_{t}^{0}=p_{t-1}$, and therefore $\mathbb{E}_{t}\left(p_{t}\right) \neq p_{t-1}$.
} 


\section{Conclusion}

The present paper has explored the effectiveness of asset markets as a tool for evaluating financial experts. We have demonstrated that expert reputation can cascade, in the sense that no new information is revealed about the expert's ability. This contrasts with the fact that markets can never be uninformative about fundamentals. As a consequence, whenever the market is in a cascade, a low-ability expert can - without any risk to his reputation - release bad information which then becomes incorporated into prices. In this case, price volatility increases and market liquidity decreases.

Reputational cascades are instrumental to understanding the role played by experts in asset price bubbles. As long as the market is informative about the type of the expert, then large price movements driven by low-ability experts are impeded on two fronts. (i) A lowability expert's reputation will on average decrease, maintaining prices low; (ii) low-ability experts tend to avoid publishing information. In a cascade, these two arguments no longer hold, and a low-ability expert inevitably exerts greater influence on prices.

A crash occurs when the market exits a reputational cascade driven by a low-ability expert. At this point, the market starts losing faith in the ability of the expert, and prices suddenly dive. This mechanism contrasts with usual arguments. Rather than being caused by the release of new information, the crash is a result of the depreciation of old information. Thus, events that may seem insignificant with respect to the underlying value of the asset can trigger large changes in asset prices, because they affect beliefs about the information that is already incorporated into prices.

The results presented here constitute a step toward understanding the role of financial experts in asset markets. 


\section{A Trader Behavior and Uniqueness}

In this section we derive an auxiliary result on trader behavior and use this to show a uniqueness result needed for our main theorem.

To shorten notation, let $A$ indicate an informed trader observing $\left(r_{t}, s_{t}\right)=(1,1), B$ an informed trader observing $(1,0), C$ an informed trader observing $(-1,1)$ and $D$ an informed trader observing $(-1,0)$. Note already that it is not possible to order the valuations of A-D generally: the ordering is history-dependent. Let in what follows $X>Y$ if the valuation of $X$ is greater than the valuation of $Y$. The following lemma gathers some preliminary observations.

Lemma 4. In equilibrium and when $\lambda_{t} \in(0,1)$ :

1. if $\theta_{t}^{G}\left(\mathcal{R}_{t-1},-1\right) \geq 0$ then $A>\{B, C\}>D$.

2. if $\theta_{t}^{G}\left(\mathcal{R}_{t-1},-1\right)<0<\theta_{t}^{G}\left(\mathcal{R}_{t-1}, 1\right)$ then $A>\{B, D\}>C$.

3. if $\theta_{t}^{G}\left(\mathcal{R}_{t-1}, 1\right) \leq 0$ then $B>\{A, D\}>C$.

Just as the ordering of the valuations of A-D depends on the entire history, so does the pattern of trade during period $t$. For instance, if $\theta_{t}^{G}\left(\mathcal{R}_{t-1},-1\right) \geq 0$ it is possible to show that - in equilibrium - $A$ buys with probability $1, D$ sells with probability 1 , while the behavior of $B$ and $C$ is indeterminate in general. By contrast, if $\theta_{t}^{G}\left(\mathcal{R}_{t-1},-1\right)<0<\theta_{t}^{G}\left(\mathcal{R}_{t-1}, 1\right)$ then $A$ buys with probability $1, C$ sells with probability 1 , while the behavior of $B$ and $D$ is indeterminate in general.

Lemma 4 is instrumental in showing the uniqueness of the cascade equilibrium. It allows us to identify the "marginal trader" in a cascade equilibrium. For instance, if $\theta_{t}^{G}\left(\mathcal{R}_{t-1},-1\right) \geq 0$ then in a cascade $A>B>C>D$. Thus, the buyer with the lowest valuation is $B$ whereas the seller with the highest valuation is $C$. The other result which is instrumental to showing uniqueness is Proposition 4, which tells us that in a cascade, $\underline{\sigma}_{t}=\underline{q}_{t}$, whereas outside a cascade $\sigma_{t}<q_{t}$. Thus, a non-cascade equilibrium would involve either $\sigma_{t}^{+}<q_{t}^{+}, \sigma_{t}^{-}<q_{t}^{-}$or both. Checking the incentives of the marginal traders, we can then show the following lemma.

Lemma 5. There exists $\tilde{\lambda}_{t} \in(0,1)$ such that if $\lambda_{t} \geq \tilde{\lambda}_{t}$ and a cascade equilibrium exists, then this equilibrium is unique. 


\section{B Information Timing}

On 18 September 2013 the Fed announced that it would continue to stimulate the US economy. Such statements are introduced directly into the computers of trading companies and converted into trades within a fraction of a second. News organizations are given previous access to the information, but can only publish it at the same time as the official statement of the Fed. Normally, the Chicago market reacts to announcements after a few miliseconds, due to the distance that information must travel from the Fed's headquarters in Washington to traders in Chicago. But in this case trading began immediately, prompting an investigation by the Fed into whether some news providers had taken the information out of the headquarters and published it from servers in Chicago. It was estimated that as much as 600 million dollars in assets changed hands in that split second, yielding huge profits to those Chicago traders who had access to the information first. ${ }^{28}$

The story illustrates that even the smallest differences in the timing of information can have tremendous impacts on trading. Thus, our assumption about the timing of information is far from innocuous and therefore we investigate it further in this section. First, we show that if information is received simultaneously, reputational cascades are impossible. Having established this result, we next build micro-foundations for the asymmetry assumption, showing that when early information acquisition is costly, it is natural for traders to better informed.

\section{B.1 Simultaneous Information Markets}

We start by showing that the assumption of a difference between traders and market makers in terms of when they receive the report is crucial for the results. If reports are received simultaneously, then the trader only has one piece of private information, which is $s_{t}$. Thus, because the price already incorporates the report, the trader's decision to buy or sell must be motivated by his information about the expert's type.

Suppose that traders and the market maker were to observe the expert's report before trade. The report $r_{t}$ is published and observed by all market participants. Moreover, suppose $\theta_{t}^{G}\left(\mathcal{R}_{t}\right)>0 .{ }^{29}$ The expected asset value of an informed trader is $\theta_{t}^{G}\left(\mathcal{R}_{t}\right)$ if he observes $s_{t}=1$, and $\lambda_{t}\left(r_{t}, 0\right) \theta_{t}^{G}\left(\mathcal{R}_{t}\right)$ if he observes $s_{t}=0$. The market maker only observes $r_{t}$, and thus before trading starts, has valuation $\lambda_{t}\left(r_{t}\right) \theta_{t}^{G}\left(\mathcal{R}_{t}\right)$. Evidently, in any equilibrium an informed trader must buy the asset with probability 1 if he observes $s_{t}=1$. Consider next the trading strategy

\footnotetext{
${ }^{28}$ Source: http://www. cnbc.com/id/101056168.

${ }^{29}$ The analysis is symmetric in the alternative $\theta_{t}^{G}\left(\mathcal{R}_{t}\right)<0$, and trivial if $\theta_{t}^{G}\left(\mathcal{R}_{t}\right)=0$.
} 
of an informed trader observing $s_{t}=0$. If he sells the asset with probability $\alpha$ then the bid price is

$$
p_{t}^{b}=\frac{\gamma \alpha}{\gamma \alpha+(1-\gamma)} \lambda_{t}\left(r_{t}, 0\right) \theta_{t}^{G}\left(\mathcal{R}_{t}\right)+\frac{1-\gamma}{\gamma \alpha+(1-\gamma)} \lambda_{t}\left(r_{t}\right) \theta_{t}^{G}\left(\mathcal{R}_{t}\right),
$$

where $\gamma=\frac{\mu}{\mu+(1-\mu) / 2}$. For any $\alpha \in[0,1]$, this is strictly greater than what he expects the asset to be worth. Thus, in any equilibrium an informed trader must sell the asset with probability 1 if he observes $s_{t}=0$. But then a reputational cascade cannot occur since the trader's action reveals his private information. This leads to the following proposition, which we state without further proof. ${ }^{30}$

Proposition 5. When all market participants acquire information simultaneously, there is never a reputational cascade.

We can easily interpret this result in terms of marginal informativeness. Simultaneous information is similar to the limit situation in which $I=0$, i.e. the report is uninformative. In this case the cutoff $\hat{\lambda}_{t}$ is one, which implies that reputational cascades never occur. Of course, when information is simultaneous the report is not uninformative in the sense of not containing information about the asset, but it is uninformative in the sense that its information is already incorporated into prices, and thus cannot be used to generate profits for the traders.

Having established this result, we move on to building a microfoundation for the asymmetry of information that will give us conditions under which it is warranted.

\section{B.2 Micro-foundations}

Proposition 5 establishes that the market is always maximally responsive when traders and the market maker observe the expert's report before trade. The assumption that traders observe the report before trade takes place, while the market maker observes the report only after trade has taken place, is thus crucial to the results of this paper. In this section, we investigate the appropriateness of this assumption.

Suppose that all market participants face the option of acquiring reports early, i.e. before trade takes place in period $t$, but that doing so involves a cost $c$. This may represent the cost of time, or efforts, needed to monitor the FE's announcement. We model competition explicitly and assume $N>1$ market makers, such that traders (including liquidity traders) buy at the lowest ask price, sell for the highest bid price, and randomize if the prices are the

\footnotetext{
${ }^{30}$ We have shown the result for $\theta_{t}^{G}\left(\mathcal{R}_{t}\right)>0$. The remaining cases are similar.
} 
same. Incentives to acquire information are inseparable from the institutional structures of the markets in which trading takes place. Although recent electronic facilities have blurred the traditional distinctions, there remains grossly speaking two basic ways to organize financial markets - exchange and over-the-counter. Since they provide complementary views we shall here consider both types of markets which, for the purpose of this paper, we shall distinguish as follows.

Definition 3. We say that the market is a financial exchange if the prices of each market maker are observable by all market participants, and that the market is over-the-counter (OTC) if each price is only observed by traders and the market maker quoting it.

In our model, the difference between the two types of markets boils down to one of public versus private prices. Whether or not prices are publicly known to all market makers should clearly make a great difference to the incentives for acquiring information. The next proposition summarizes this section's principal results, and supports our assumption regarding the timing of information acquisition.

\section{Proposition 6.}

1. If the market is a financial exchange then there exists $\bar{c}$ such that for $0<c<\bar{c}$ informed traders acquire reports early while market makers do not.

2. If the market is OTC then there exist $\underline{c}$ and $\bar{c}$, both greater than zero, such that for $\underline{c}<c<\bar{c}$ informed traders acquire reports early while market makers do not.

The first part of the proposition is a straightforward instance of the Grossman and Stiglitz (1980) paradox. ${ }^{31}$ A market maker who acquires information early can attempt to undercut his competitors. However he reveals by doing so that the asset is overvalued, and will in turn be undercut until all arbitrage opportunities are exhausted. But then paying $c>0$ to acquire information was wasteful in the first place.

The opacity of OTC markets makes the acquisition of information relatively more profitable than is the case for exchanges. While no market maker can sell the asset for more than his competitors - nor buy it for less - an informed market maker can on the other hand select the trades which he wishes to engage in. For instance, if a market maker believes the asset to

\footnotetext{
${ }^{31}$ The Grossman-Stiglitz paradox says that if a market were informationally efficient, that is, all relevant information is already reflected in market prices, then no single agent would have sufficient incentives to acquire the information on which prices are based.
} 
be undervalued because he has observed $r_{t}=1$ he can then refuse to sell the asset at a price $p_{t}^{a}$ (by raising his own ask price) while still accepting to buy the asset for a price $p_{t}^{b}$ which he knows to be cheap. In contrast to the case of financial exchanges, market makers thus do have incentives to acquire information early in OTC markets. Nevertheless, it should be clear that - on average - market makers are unable to trade profitably with informed traders. The probability of a profitable trade is thus at most $1-\mu$ for market makers, while it is exactly 1 for informed traders. We show that, as a consequence, incentives to acquire information early are always greater for traders than they are for market makers. Thus, for some intermediate cost range, traders will acquire reports early while market makers will not.

\section{Proofs}

Proof of Lemma 1: Let $M_{t}(x)=\frac{\lambda_{t} x}{\lambda_{t} x+1-\lambda_{t}}$ and define $l_{t}=\frac{\mathbb{P}_{t}\left(r_{t}, y_{t} \mid G\right)}{\mathbb{P}_{t}\left(r_{t}, y_{t} \mid B, \sigma_{t}^{t}\right)}$ to be the likelihood ratio of the period $t$ outcome. Thus, $\lambda_{t}=M_{t}(1)$ and $\lambda_{t+1}=M_{t}\left(l_{t}\right)$. At the beginning of period $t$ the likelihood ratio $l_{t}$ is a random variable. As in the text we can define the expected reputation conditional on $r_{t}$. Here it will be convenient to condition also on the strategy, so we write $\lambda_{t+1}^{e}\left(r_{t}, \sigma_{t}^{r_{t}}\right)=\mathbb{E}_{t}\left(\lambda_{t+1} \mid r_{t}, \sigma_{t}^{r_{t}}, B\right)$. First, notice that

$$
l_{t}=\frac{q_{t}^{r_{t}}}{\sigma_{t}^{r_{t}}} \cdot \frac{\mathbb{P}\left(y_{t} \mid r_{t}, G\right)}{\mathbb{P}\left(y_{t} \mid r_{t}, B\right)} .
$$

This is well-defined since $\sigma_{t}^{r_{t}}>0$ always. ${ }^{32}$ Hence $\lambda_{t}^{e}\left(r_{t}, \sigma_{t}^{r_{t}}\right)$ is strictly decreasing in $\sigma_{t}^{r_{t}}$.

The first part of the equilibrium condition (2) can be written as

$$
\lambda_{t}^{e}\left(-1, \sigma_{t}^{-}\right)-\lambda_{t}^{e}\left(0,1-\sigma_{t}^{+}-\sigma_{t}^{-}\right)=0 .
$$

The derivative of the left-hand side with respect to $\sigma_{t}^{+}$and $\sigma_{t}^{-}$is always strictly negative. Furthermore, if $\sigma_{t}^{-}=0$ the left-hand side is positive and if $\sigma_{t}^{-}=1-\sigma_{t}^{+}$the left-hand side is negative. Therefore, there exists an implicit function $f\left(\sigma_{t}^{+}\right)$such that $\sigma_{t}^{-}=f\left(\sigma_{t}^{+}\right)$solves

\footnotetext{
${ }^{32}$ To see that $\sigma_{t}^{r_{t}}>0$, notice that $q_{t}^{r}>0$ for all $r$. If $\sigma_{t}^{r}=0$ for some $r$, we would have $\lambda_{t}\left(r, y_{t}, 0\right)=1$, and the expert could gain perfect reputation by choosing $r_{t}=r$. This is a contradiction.
} 
(10). Remark that $\frac{\partial \lambda_{t}^{e}\left(0,1-\sigma_{t}^{+}-\sigma_{t}^{-}\right)}{\partial \sigma_{t}^{+}}=\frac{\partial \lambda_{t}^{e}\left(0,1-\sigma_{t}^{+}-\sigma_{t}^{-}\right)}{\partial \sigma_{t}^{-}}$. Implicit differentiation then gives

$$
f^{\prime}\left(\sigma_{t}^{+}\right)=-\left[\frac{-\frac{\partial \lambda_{t}^{e}\left(0,1-\sigma_{t}^{+}-\sigma_{t}^{-}\right)}{\partial \sigma_{t}^{-}}}{\frac{\partial \lambda_{t}^{e}\left(-1, \sigma_{t}^{-}\right)}{\partial \sigma_{t}^{-}}-\frac{\partial \lambda_{t}^{e}\left(0,1-\sigma_{t}^{+}-\sigma_{t}^{-}\right)}{\partial \sigma_{t}^{-}}}\right] .
$$

Both the nominator and the denominator of the fraction are negative. Hence, $f^{\prime}\left(\sigma_{t}^{+}\right) \in(-1,0)$.

Now, let

$$
\Delta_{t}\left(\sigma_{t}^{+}, \sigma_{t}^{-}\right)=\lambda_{t}^{e}\left(+1, \sigma_{t}^{+}\right)-\lambda_{t}^{e}\left(0,1-\sigma_{t}^{+}-\sigma_{t}^{-}\right)
$$

The second equilibrium condition from (2) can be written as $\Delta_{t}\left(\sigma_{t}^{+}, \sigma_{t}^{-}\right)=0$. Notice that $\Delta_{t}(\cdot)$ is strictly decreasing in both arguments. Using the implicit function derived above we can combine the two equilibrium conditions and reduce (2) to a single condition: $\Delta_{t}\left(\sigma_{t}^{+}, f\left(\sigma_{t}^{+}\right)\right)=$ 0 . Then

$$
\frac{d \Delta_{t}\left(\sigma_{t}^{+}, f\left(\sigma_{t}^{+}\right)\right)}{d \sigma_{t}^{+}}=\frac{d \lambda_{t}^{e}\left(+1, \sigma_{t}^{+}\right)}{d \sigma_{t}^{+}}-\frac{d \lambda_{t}^{e}\left(0,1-\sigma_{t}^{+}-\sigma_{t}^{-}\right)}{d \sigma_{t}^{+}}\left(1+f^{\prime}\left(\sigma_{t}^{+}\right)\right)<0 .
$$

This implies uniqueness of the best-response strategy. Existence follows from noting that $\Delta_{t}(0, f(0)) \geq 0$ while $\Delta_{t}(1, f(1)) \leq 0$. We now show the two remaining statements of the lemma.

\section{Part 1.}

Whenever $\underline{\xi}_{t}^{y_{t}}\left(r_{t}, 1\right)=\underline{\xi}_{t}^{y_{t}}\left(r_{t}, 0\right)$ we have $l_{t}=\frac{q_{t}^{r_{t}}}{\sigma_{t}^{r_{t}}}$. Thus, if $\underline{\sigma}_{t}=\underline{q}_{t}$ then $\mathbb{E}_{t}\left(\lambda_{t+1} \mid B\right)=\lambda_{t}$. Notice that

$$
\mathbb{E}_{t}\left(l_{t} \mid B\right)=\sum_{r_{t}} \sigma_{t}^{r_{t}} \sum_{y_{t}} \mathbb{P}\left(y_{t} \mid r_{t}, B\right)\left[\frac{q_{t}^{r_{t}}}{\sigma_{t}^{r_{t}}} \cdot \frac{\mathbb{P}\left(y_{t} \mid r_{t}, G\right)}{\mathbb{P}\left(y_{t} \mid r_{t}, B\right)}\right]=1 .
$$

Suppose $\sigma_{t}^{r_{t}} \neq q_{t}^{r_{t}}$ for some $r_{t}$, such that $l_{t}$ is not constant. The concavity of $M_{t}(\cdot)$ and Jensen's inequality then imply that

$$
\mathbb{E}_{t}\left(M_{t}\left(l_{t}\right) \mid B\right)<M_{t}\left(\mathbb{E}_{t}\left(l_{t} \mid B\right)\right)=M_{t}(1) .
$$

This implies that $\mathbb{E}_{t}\left(\lambda_{t+1} \mid B\right)<\lambda_{t}$. Clearly, this cannot be optimal for the expert.

Part 2.

Now, we will show that $\sigma_{t}<q_{t}$ whenever $\underline{\xi}_{t}^{y t}\left(r_{t}, 1\right) \neq \underline{\xi}_{t}^{y t}\left(r_{t}, 0\right)$ for some $\left(y_{t}, r_{t}\right)$. We can 
repeat the arguments from Part 1 to show that this implies that $\mathbb{E}_{t}\left(\lambda_{t+1} \mid B\right)<\lambda_{t}$ regardless of $\underline{\sigma}_{t}$. Consequently, in equilibrium $\lambda_{t+1}^{e}\left(r_{t}, \sigma_{t}^{r_{t}}\right)<\lambda_{t}$ for all $r_{t}$.

Since $q_{t}^{0}=1-q_{t}, \sigma_{t}^{0}=1-\sigma_{t}$ and $\mathbb{P}\left(s_{t}=0 \mid r_{t}=0\right)=1$, then $\lambda_{t+1}^{e}\left(0, \sigma_{t}^{0}\right)=M_{t}\left(\frac{1-q_{t}}{1-\sigma_{t}}\right)$. This is increasing in $\sigma_{t}$. Then $\lambda_{t+1}^{e}\left(0, \sigma_{t}^{0}\right)<\lambda_{t}$ can only be true if $\sigma_{t}<q_{t}$.

Proof of Lemma 2: To establish uniqueness notice that since by definition $\lambda_{t}$ is given at the beginning of period $t$, valuations $v_{t}(\cdot)$ depend only on $\underline{\sigma}_{t}$. Recall that the price is given by $p_{t}^{y_{t}}=$ $\mathbb{E}_{t}\left(\theta_{t} \mid y_{t}, p_{t}^{y_{t}}\right)$. The right-hand side of this equation is non-decreasing in $p_{t}^{y_{t}}$ if $\mathbb{E}_{t}\left[\theta_{t} \mid y_{t}, p_{t}^{y_{t}}\right]>p_{t}^{y_{t}}$ and non-increasing in $p_{t}^{y_{t}}$ if $\mathbb{E}_{t}\left[\theta_{t} \mid y_{t}, p_{t}^{y_{t}}\right]<p_{t}^{y_{t}}$. Thus $p_{t}^{y_{t}}$ is uniquely determined.

If $\theta_{t}^{g}\left(\mathcal{R}_{t-1},-1\right) \geq 0$ then $p_{t}^{b}<p_{t}^{0}<p_{t}^{a}$ follows from the fact that $\max _{\left(r_{t}, s_{t}\right)}\left\{v_{t}\left(r_{t}, s_{t}\right)\right\}>$ $p_{t}^{0}>\min _{\left(r_{t}, s_{t}\right)}\left\{v_{t}\left(r_{t}, s_{t}\right)\right\}$, which is shown in the proof of Lemma 4. Other cases can be proven similarly.

Proof of Lemma 3: Part 1 is immediate, since by definition of a reputational cascade no information about expert type reaches the market.

We next show parts 2 and 3 . Suppose that $\theta_{t}^{G}\left(\mathcal{R}_{t-1},-1\right) \geq 0$ (the proofs for the remaining cases follow similar lines and are therefore omitted). We show in Appendix A that a trader who observes $\left(r_{t}, s_{t}\right)=(1,1)$ buys the asset with probability 1 while a trader who observes $\left(r_{t}, s_{t}\right)=(-1,0)$ sells the asset with probability 1 . Thus if a trader with $\left(r_{t}, s_{t}\right)=(1,0)$ does not buy the asset with probability 1 then $\mathbb{P}_{t}\left(y_{t}=a, r_{t}=1 \mid G\right)>\mathbb{P}_{t}\left(y_{t}=a, r_{t}=1 \mid B\right)$, contradicting (9). Similarly if a trader with $\left(r_{t}, s_{t}\right)=(-1,1)$ does not sell the asset with probability 1 then $\mathbb{P}_{t}\left(y_{t}=b, r_{t}=-1 \mid G\right)<\mathbb{P}_{t}\left(y_{t}=b, r_{t}=-1 \mid B\right)$, contradicting (9).

Proof of Proposition 2: According to Proposition 4, in a reputational cascade then $\underline{\sigma}_{t}=\underline{q}_{t}$. This implies, among other things, that if the market is in a reputational cascade then a trader observing $\left(r_{t}, s_{t}\right)=(0,0)$ learns nothing about the asset nor about the expert. Thus $v_{t}(0,0)=p_{t}^{0}$ and, since by Lemma 2 we have $p_{t}^{a}>p_{t}^{0}>p_{t}^{b}$, this trader abstains.

We split the rest of the proof into four cases. 
Case 1: Suppose $\theta_{t}^{G}\left(\mathcal{R}_{t-1},-1\right) \geq 0$. By Lemma 4, a trader with $\left(r_{t}, s_{t}\right)=(1,1)$ buys the asset with probability 1 while a trader with $\left(r_{t}, s_{t}\right)=(-1,0)$ sells the asset with probability 1 . A reputational cascade thus occurs if and only if (i) a trader with $\left(r_{t}, s_{t}\right)=(1,0)$ buys always and (ii) a trader with $\left(r_{t}, s_{t}\right)=(-1,1)$ sells always. The necessary and sufficient conditions for a cascade to be supported in equilibrium are thus that $(\mathrm{i}) v_{t}(1,0)$ is no less than the weighted average of $v_{t}(1,1)$ on the one hand and the valuation of a liquidity trader on the other hand (viz. $\left.p_{t}^{0}\right)$, and (ii) $v_{t}(1,1)$ is no more than the weighted average of $v_{t}(-1,0)$ on the one hand and the valuation of a liquidity trader on the other hand.

The first condition can be written as

$\frac{\lambda_{t}(1-\pi) q_{t}^{+}}{\lambda_{t}(1-\pi) q_{t}^{+}+\left(1-\lambda_{t}\right) q_{t}^{+}} \cdot \theta_{t}^{G}\left(\mathcal{R}_{t-1}, 1\right) \geq \frac{\gamma \lambda_{t} q_{t}^{+}}{\gamma q_{t}^{+}+1-\gamma} \cdot \theta_{t}^{G}\left(\mathcal{R}_{t-1}, 1\right)+\frac{1-\gamma}{\gamma q_{t}^{+}+1-\gamma} \lambda_{t} \cdot \theta_{t}^{G}\left(\mathcal{R}_{t-1}\right)$,

where $\gamma=\frac{\mu}{\mu+(1-\mu) / 2}$, as defined in Appendix B. This is satisfied for $\lambda_{t} \geq \hat{\lambda}_{t}^{+}$, where

$$
\hat{\lambda}_{t}^{+}=1-\frac{1-\pi}{\pi} \cdot \frac{(1-\gamma)\left(1-\frac{\theta_{t}^{G}\left(\mathcal{R}_{t-1}\right)}{\theta_{t}^{G}\left(\mathcal{R}_{t-1}, 1\right)}\right)}{\gamma q_{t}^{+}+(1-\gamma) \frac{\theta_{t}^{G}\left(\mathcal{R}_{t-1}\right)}{\theta_{t}^{G}\left(\mathcal{R}_{t-1}, 1\right)}}
$$

The second condition can be written as

$$
\theta_{t}^{G}\left(\mathcal{R}_{t-1},-1\right) \leq \frac{\gamma \lambda_{t} q_{t}^{-}}{\gamma q_{t}^{-}+1-\gamma} \cdot \theta_{t}^{G}\left(\mathcal{R}_{t-1},-1\right)+\frac{1-\gamma}{\gamma q_{t}^{-}+1-\gamma} \lambda_{t} \cdot \theta_{t}^{G}\left(\mathcal{R}_{t-1}\right)
$$

This in turn is satisfied for $\lambda_{t} \geq \hat{\lambda}_{t}^{-}$, where

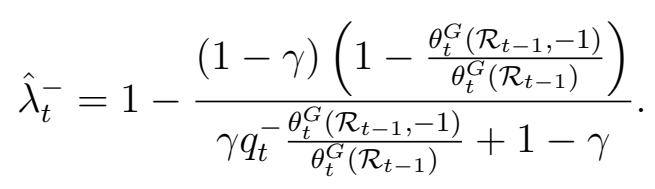

Letting $\hat{\lambda}_{t}=\max \left\{\hat{\lambda}_{t}^{+}, \hat{\lambda}_{t}^{-}\right\}$, the previous arguments thus establish that a cascade equilibrium exists if and only if $\lambda_{t} \geq \hat{\lambda}_{t}$. Lemma 5 concludes the proof of the proposition.

Case 2: Suppose now $\theta_{t}^{G}\left(\mathcal{R}_{t-1}\right)>0>\theta_{t}^{G}\left(\mathcal{R}_{t-1},-1\right)$. In this case, $\hat{\lambda}_{t}^{+}$is given by (11), whereas

$$
\hat{\lambda}_{t}^{-}=1-\frac{1-\pi}{\pi} \cdot \frac{(1-\gamma)\left(1-\frac{\theta_{t}^{G}\left(\mathcal{R}_{t-1}\right)}{\theta_{t}^{G}\left(\mathcal{R}_{t-1},-1\right)}\right)}{\gamma q_{t}^{-}+(1-\gamma) \frac{\theta_{t}^{G}\left(\mathcal{R}_{t-1}\right)}{\theta_{t}^{G}\left(\mathcal{R}_{t-1},-1\right)}}<\hat{\lambda}_{t}^{+} .
$$


The inequality follows from $\frac{\theta_{t}^{G}\left(\mathcal{R}_{t-1}\right)}{\theta_{t}^{G}\left(\mathcal{R}_{t-1},-1\right)}<0<\frac{\theta_{t}^{G}\left(\mathcal{R}_{t-1}\right)}{\theta_{t}^{G}\left(\mathcal{R}_{t-1}, 1\right)}$ and the fact that $\theta_{t}^{G}\left(\mathcal{R}_{t-1}\right)>0$ implies $q_{t}^{+}>q_{t}^{-}$. Thus $\hat{\lambda}_{t}=\hat{\lambda}_{t}^{+}$. The remaining arguments are identical to Case 1 .

Case 3: Suppose now $\theta_{t}^{G}\left(\mathcal{R}_{t-1},-1\right)<0<\theta_{t}^{G}\left(\mathcal{R}_{t-1}\right)$. The analysis is similar to Case 2 .

Case 4: Suppose now $\theta_{t}^{G}\left(\mathcal{R}_{t-1}, 1\right) \leq 0$. The analysis is similar to Case 1 .

Proof of Proposition 3: Immediate from inspection of (11) and (12).

Proof of Theorem 1: Consider history $\mathcal{H}_{t}$ such that $\theta_{t}^{G}\left(\mathcal{R}_{t-1},-1\right)>0$. The remaining cases can be established similarly. We begin by showing that for $\lambda_{t}$ small then $\gamma$ big enough implies that $\lambda_{t+1}$ becomes arbitrarily large with positive probability. Observe that $\lambda_{t} \rightarrow 0$ implies $p_{t}^{a} \rightarrow 0$. Given $\theta_{t}^{G}\left(\mathcal{R}_{t-1},-1\right)>0$, we have on the other hand $v_{t}(1,1)>0$ and $v_{t}(-1,1)>0$. This shows that for $\lambda_{t}$ small, traders with $\left(r_{t}, s_{t}\right)=(1,1)$ and $(-1,1)$ buy the asset with probability 1 . We also know that $\left(r_{t}, s_{t}\right)=(-1,0)$ sells the asset with probability 1. So $r_{t}=-1$ followed by $y_{t}=a$ induces reputation $\lambda_{t+1}=M_{t}\left(\frac{q_{t}^{-}}{\sigma_{t}^{-}} \cdot \frac{\gamma \pi+(1-\gamma)}{1-\gamma}\right)$. The numerator of the fraction is bounded below by $\frac{1}{2}(1-\phi)[\gamma \pi+(1-\gamma)]$ and thus, if $\gamma$ goes to one, the fraction goes to positive infinity. Noting that $\lim _{x \rightarrow \infty} M_{t}(x)=1$ then establishes the claim.

Proposition 2 in conjunction with the claim above (and the fact that due to liquidity traders any history occurs with positive probability) finishes to establish the first part of the theorem, while Propositions 2 and 3 together establish the second part of the theorem.

Proof of Lemma 4: We prove the first case. Other cases can be proven along similar lines. That $A>B$ and $C>D$ is immediate from (5) and (6). We now show that $A>p_{t}^{0}>D$. That $A>p_{t}^{0}$ is obvious. Notice further that in order to show $p_{t}^{0}>D$ it is enough to show that $\beta_{t}(-1,0) \leq \lambda_{t}$. So suppose $\beta_{t}(-1,0)>\lambda_{t}$. Clearly then $\lambda_{t}^{e}(-1) \geq \beta_{t}(-1,0)$. Thus $\lambda_{t}^{e}(-1)>\lambda_{t}$. But we have shown in Proposition 4 that $\lambda_{t}^{e}(0) \leq \lambda_{t}$. Hence $\lambda_{t}^{e}(0)<\lambda_{t}^{e}(-1)$, which cannot be in equilibrium. This concludes the proof. 
Proof of Lemma 5: We work the proof for the case where $\theta_{t}^{G}\left(\mathcal{R}_{t-1},-1\right) \geq 0$. The remaining cases are similar, and therefore omitted.

We first establish an intermediary claim, namely that for $\lambda_{t}$ high enough then, in any equilibrium, a trader observing $\left(r_{t}, s_{t}\right)=(0,0)$ abstains. First, observe that $v_{t}(0,0)$ tends to $p_{t}^{0}$ as $\lambda_{t}$ tends to 1 . Using lemma 2 , it therefore only remains to show that both bid and ask prices are bounded away from $p_{t}^{0}$ when $\lambda_{t}$ tends to 1 . That $p_{t}^{a}$ is bounded away from $p_{t}^{0}$ follows from the fact that $v_{t}(1,1)>p_{t}^{0}$ while the probability of an informed trader with $\left(r_{t}, s_{t}\right)=(1,1)$ is $\mu \lambda_{t} q_{t}^{+} \pi \geq \frac{1}{2}(1-\phi) \mu \lambda_{t} \pi \rightarrow_{\lambda_{t} \rightarrow 1} \frac{1}{2}(1-\phi) \mu \pi>0$. In a similar way, that $p_{t}^{b}$ is bounded away from $p_{t}^{0}$ follows from the fact that $v_{t}(-1,0)<p_{t}^{0}$ while the probability of an informed trader with $\left(r_{t}, s_{t}\right)=(-1,0)$ is at least $\mu \lambda_{t} q_{t}^{-}(1-\pi) \geq \frac{1}{2}(1-\phi) \mu \lambda_{t}(1-\pi) \rightarrow_{\lambda_{t} \rightarrow 1} \frac{1}{2}(1-\phi) \mu(1-\pi)>0$. We have thus established the claim, and henceforth assume $\lambda_{t}$ high enough so as to ignore traders with $\left(r_{t}, s_{t}\right)=(0,0)$.

It will be useful in what follows to augment the notation and let $v_{t}\left(r_{t}, s_{t}, \sigma_{t}^{r_{t}}\right)$ denote an informed trader's valuation, in order to reflect the fact that the latter depends in general on the strategy of a bad expert. As noted in the body of the paper, a non-cascade equilibrium must involve either $\sigma_{t}^{+}<q_{t}^{+}, \sigma_{t}^{-}<q_{t}^{-}$or both. We consider each of these possibilities in turn.

Case 1. Suppose $\sigma_{t}^{+}<q_{t}^{+}$. Note then that $v_{t}\left(1,0, \sigma_{t}^{+}\right)>v_{t}\left(1,0, q_{t}^{+}\right)$. By definition of a cascade equilibrium, $v_{t}\left(1,0, q_{t}^{+}\right)$is no less than the weighted average of the valuations of liquidity traders on the one hand and informed traders observing $\left(r_{t}, s_{t}\right)=(1,1)$ on the other hand. The same thus holds - with strict inequality - for $v_{t}\left(1,0, \sigma_{t}^{+}\right)$, and establishes that in the non-cascade equilibrium a trader observing $\left(r_{t}, s_{t}\right)=(1,0)$ must be buying the asset with probability 1 . But then $\lambda_{t+1}^{e}(1)>\lambda_{t}$, which is impossible in an equilibrium.

Case 2. Suppose $\sigma_{t}^{+} \geq q_{t}^{+}$. By implication $\sigma_{t}^{-}<q_{t}^{-}$and, in turn, $v_{t}\left(-1,0, \sigma_{t}^{-}\right)>v_{t}\left(-1,0, q_{t}^{-}\right)$. Compared with the cascade equilibrium, the weighted average of the valuations of liquidity traders and traders with $\left(r_{t}, s_{t}\right)=(-1,0)$ is thus strictly greater in the non-cascade equilibrium. So either (i) $p_{t}^{b}>v_{t}(-1,1)$, or (ii) traders with $\left(r_{t}, s_{t}\right)=(1,0)$ are selling the asset and pushing the bid price down. Case (i) is ruled out, since it would involve $\lambda_{t+1}^{e}(-1)>\lambda_{t}$, which is impossible in an equilibrium. Case (ii) on the other hand implies that, conditional 
on $r_{t}=-1$, traders with $s_{t}=0$ never trade according to traders with $s_{t}=1$. Given that $\sigma_{t}^{+} \geq q_{t}^{+}$and $\sigma_{t}^{-}<q_{t}^{-}$, we thus have $\lambda_{t+1}^{e}(-1)>\lambda_{t+1}^{e}(1)$, contradicting (2).

Proof of Proposition 6: The proof of the first part essentially consists of the arguments presented in the body of the paper. The threshold $\bar{c}$ can here be chosen to be any number lesser or equal than the expected profits made by informed traders when these acquire information early but market makers do not. We now prove the second part, concerning OTC markets. We do this in two steps.

Step 1. Incentives to acquire information. When a player does not acquire early information he expects zero payoff. Suppose now that $c$ is such that traders acquire information early. Since they learn more from the reports than market makers (they observe $s_{t}$ ), it ensues that market makers cannot on average gain against informed traders. Market makers only profit when a liquidity trader reveals himself by trading "against the market". Under these assumptions, a market maker's willingness-to-pay for information is ${ }^{33}$

$$
\Pi_{M M}=\frac{1-\mu}{2} \sum_{r_{t}} \mathbb{P}\left(r_{t}\right)\left[\max \left\{0, \mathbb{E}_{t}\left[\theta_{t} \mid r_{t}\right]-p_{t}^{b}\right\}+\max \left\{0, p_{t}^{a}-\mathbb{E}_{t}\left[\theta_{t} \mid r_{t}\right]\right\}\right]
$$

The first term is profit made from buying when the bid price is too low, and the second term is the probability of selling when the ask price is too high. Any other trade is denied by the MM. ${ }^{34}$ A trader's willingness-to-pay for information is

$$
\Pi_{I T}=\sum_{r_{t}, s_{t}} \mathbb{P}\left(r_{t}, s_{t}\right) \max \left\{0, \mathbb{E}_{t}\left[\theta_{t} \mid r_{t}, s_{t}\right]-p_{t}^{a}, p_{t}^{b}-\mathbb{E}_{t}\left[\theta_{t} \mid r_{t}, s_{t}\right]\right\}
$$

Now, observe that an uninformed market maker gains on liquidity traders and loses on informed traders. In particular, his profits are $(1-\mu) \Pi_{L T}-\mu \Pi_{I T}$, where the gain on liquidity

\footnotetext{
${ }^{33}$ If there is more than one ask price and one bid price then choose $p_{t}^{a}$ to be the lowest ask price offered and $p_{t}^{b}$ to be the highest bid price offered.

${ }^{34} \mathrm{By}$ setting his ask price lower than the market, or his bid price higher.
} 
traders is

$$
\begin{aligned}
(1-\mu) \Pi_{L T} & =\frac{1-\mu}{2}\left[p_{t}^{a}-p_{t}^{b}\right] \\
& =\frac{1-\mu}{2} \sum_{r_{t}} \mathbb{P}\left(r_{t}\right)\left[\left(\mathbb{E}_{t}\left[\theta_{t} \mid r_{t}\right]-p_{t}^{b}\right)+\left(p_{t}^{a}-\mathbb{E}_{t}\left[\theta_{t} \mid r_{t}\right]\right)\right] \\
& =\Pi_{M M}-\bar{\Pi},
\end{aligned}
$$

and

$$
\bar{\Pi}=\frac{1-\mu}{2} \sum_{r_{t}} \mathbb{P}\left(r_{t}\right)\left[\max \left\{0, p_{t}^{b}-\mathbb{E}_{t}\left[\theta_{t} \mid r_{t}\right]\right\}+\max \left\{0, \mathbb{E}_{t}\left[\theta_{t} \mid r_{t}\right]-p_{t}^{a}\right\}\right]
$$

Uninformed market makers make zero profits, i.e. $(1-\mu) \Pi_{L T}-\mu \Pi_{I T}=0$. We can use this to rewrite the informed market maker's gain as

$$
\begin{aligned}
\Pi_{M M} & =\bar{\Pi}+\mu \Pi_{I T} \\
& <(1-\mu) \sum_{r_{t}} \mathbb{P}\left(r_{t}\right) \max \left\{0, \mathbb{E}_{t}\left[\theta_{t} \mid r_{t}\right]-p_{t}^{a}, p_{t}^{b}-\mathbb{E}_{t}\left[\theta_{t} \mid r_{t}\right]\right\}+\mu \Pi_{I T} \\
& \leq(1-\mu) \sum_{r_{t}, s_{t}} \mathbb{P}\left(r_{t}, s_{t}\right) \max \left\{0, \mathbb{E}_{t}\left[\theta_{t} \mid r_{t}, s_{t}\right]-p_{t}^{a}, p_{t}^{b}-\mathbb{E}_{t}\left[\theta_{t} \mid r_{t}, s_{t}\right]\right\}+\mu \Pi_{I T} \\
& =\Pi_{I T} .
\end{aligned}
$$

Thus, when traders acquire information, they always have more incentive to do so than market makers.

Step 2. Identifying cost thresholds. Step 1 shows us that if we set $\bar{c}=\Pi_{M M}$ and $\underline{c}=\Pi_{I T}$, then for $c \in(\underline{c}, \bar{c})$ it is an equilibrium for traders to acquire information early, and for no market maker to do so. Notice that it cannot be an equilibrium for market makers to acquire information and traders not to do so. Suppose all market makers acquire early information. Competition would then drive profits to zero, and information acquisition is not optimal. Suppose then $M<N$ market makers acquire early information. In that case, traders can still trade with uninformed market makers, and the arguments of Step 1 are valid. Thus, the unique equilibrium is for traders only to acquire early information. 
Proof of Result 1: When the market is in a reputational cascade, the trading frequency is $\mu q_{t}+(1-\mu)$, since good and bad experts induce trades with the same probability. Outside a cascade, the expected frequency is bounded above by

$$
\max \left\{\mu\left(\lambda_{t} q_{t}(1-\pi)+\left(1-\lambda_{t}\right) \sigma_{t}\right), \mu \lambda_{t} q_{t} \pi\right\}+1-\mu .
$$

Clearly, this is lower than $\mu q_{t}+(1-\mu)$ since $\sigma_{t}<q_{t}$ by Proposition 4 .

Proof of Result 2: If $\theta_{t}^{G}\left(\mathcal{R}_{t-1}\right)>0$, it is easy to show that $q_{t}^{+}>q_{t}^{-}$. Since a price increase (decrease) occurs only after a buy (sell), the statement of the result follows immediately.

Proof of Result 3: We will show the result for the fixed value case. Denote by $n_{t}=$ $\#_{s \leq t}\left(x_{s}=1\right)$ the number of positive reports, $m_{t}=\#_{s \leq t}\left(x_{s}=-1\right)$ the number of negative reports, and $d_{t}=n_{t}-m_{t}$. Inspection of (11) and (12) shows us that $\hat{\lambda}_{t}$ depends only on $\lambda_{t}$ and the marginal informativeness $\left(I_{t}^{+}, I_{t}^{-}\right)$. Thus, in a cascade $\hat{\lambda}_{t}$, depends only on $\left(I_{t}^{+}, I_{t}^{-}\right)$. Furthermore, Proposition 3 shows that $\hat{\lambda}_{t}$ is decreasing in $I_{t}$. The last thing we need to show is that $I_{t}$ is strictly increasing in $\left|d_{t}\right|$. Observe that $I_{t}^{+}=I^{+}\left(d_{t}\right)=1-\frac{1-\Phi^{d_{t}}}{1+\Phi^{d_{t}}} \frac{1+\Phi^{d_{t}+1}}{1-\Phi^{d_{t}+1}}$ and $I_{t}^{-}=I^{-}\left(d_{t}\right)=1-\frac{1-\Phi^{d_{t}}}{1+\Phi^{d_{t}}} \frac{1+\Phi^{d_{t}-1}}{1-\Phi^{d_{t}-1}}$. It is easy to see from that $I_{t}^{+}\left(d_{t}\right)=I_{t}^{-}\left(-d_{t}\right)$, and differentiation gives us that for $r \in\{-,+\}$ then $I^{r}\left(d_{t}\right)$ is increasing (decreasing) in $d_{t}$ when $d_{t}>0\left(d_{t}<0\right)$. It follows that sensitivity must be higher at the end of a cascade than before.

Proof of Result 4: This result has been shown in the proof of Lemma 1.

Proof of Result 5: In a cascade all traders who see $r_{t}=1$ buy and this is the unique equilibrium (see Lemma 5 above). Thus $v\left(1, s_{t}\right)>\hat{p}_{t}^{a}$. Inspecting the price equation (7), we 
can see that $\tilde{p}_{t}^{a}=\alpha \hat{p}_{t}^{a}+(1-\alpha) v\left(1, s^{\prime}\right)$ for some $\alpha \in(0,1)$ and $s^{\prime} \in\{0,1\}$. Hence $\tilde{p}_{t}^{a}>\hat{p}_{t}^{a}$. The argument is similar for $p_{t}^{b}$, and is therefore omitted.

Proof of Result 6: Since $\mathbb{E}_{t}\left(\hat{p}_{t}\right)=\mathbb{E}_{t}\left(\tilde{p}_{t}\right)=p_{t}^{0}$, then Results 1 and 5 imply that the distribution of $\tilde{p}_{t}$ is a mean-preserving spread of the distribution of $\hat{p}_{t}$. The conclusion then follows from the convexity of the variance function. 


\section{References}

Abreu, D., Brunnermeier, M. K., 2003. Bubbles and Crashes. Econometrica 71 (1), 173-204.

Admati, A. R., Pfleiderer, P., 1986. A Monopolistic Market for Information. Journal of Economic Theory 39 (2), 400-438.

Allen, F., Gale, D., 1992. Stock-price Manipulation. Review of Financial Studies 5 (3), 503529.

Allen, F., Gorton, G., 1993. Churning Bubbles. Review of Economic Studies 60 (4), 813-836.

Avery, C., Zemsky, P., 1998. Multidimensional Uncertainty and Herd Behavior in Financial Markets. American Economic Review 88 (4), 724-748.

Barlevy, G., Veronesi, P., 2003. Rational Panics and Stock Market Crashes. Journal of Economic Theory 110 (2), 234-263.

Benabou, R., Laroque, G., 1992. Using Privileged Information to Manipulate Markets: Insiders, Gurus, and Credibility. Quarterly Journal of Economics 107 (3), 921-958.

Cuoco, D., Kaniel, R., 2011. Equilibrium Prices in the Presence of Delegated Portfolio Management. Journal of Financial Economics 101 (2), 264-296.

Dasgupta, A., Prat, A., 2006. Financial Equilibrium with Career Concerns. Theoretical Economics 1 (1), 67-93.

Dasgupta, A., Prat, A., 2008. Information Aggregation in Financial Markets with Career Concerns. Journal of Economic Theory 143 (1), 83-113.

Dasgupta, A., Prat, A., Verardo, M., 2011. The Price Impact of Institutional Herding. Review of Financial Studies 24 (3), 892-925.

DeLong, J., Shleifer, A., Summers, L. H., Waldmann, R. J., 1990. Positive Feedback Investment Strategies and Destabilizing Rational Speculation. Journal of Finance 45 (2), 379-395.

Gennotte, G., Leland, H., 1990. Market Liquidity, Hedging, and Crashes. American Economic Review 80 (5), pp. 999-1021. 
Glosten, L. R., Milgrom, P. R., 1985. Bid, Ask and Transaction Prices in a Specialist Market with Heterogeneously Informed Traders. Journal of Financial Economics 14 (1), 71-100.

Grossman, S., 1976. On the Efficiency of Competitive Stock Markets Where Trades Have Diverse Information. Journal of Finance 31 (2), 573-585.

Grossman, S. J., Stiglitz, J. E., 1980. On the Impossibility of Informationally Efficient Markets. American Economic Review 70 (3), 393-408.

Guerrieri, V., Kondor, P., 2012. Fund Managers, Career Concerns, and Asset Price Volatility. American Economic Review 102 (5), 1986-2017.

Jacklin, C. J., Kleidon, A. W., Pfeiderer, P., 1992. Underestimation of Portfolio Insurance and the Crash of October 1987. Review of Financial Studies 5 (1), 35-63.

Kaniel, R., Kondor, P., 2013. The Delegated Lucas Tree. Review of Financial Studies 26 (4), 929-984.

Kyle, A. S., 1985. Continuous Auctions and Insider Trading. Econometrica 53 (6), 1315-1335.

Lee, I. H., 1998. Market Crashes and Informational Avalanches. Review of Economic Studies 65 (4), 741-759.

Ottaviani, M., Sørensen, P. N., 2006a. Professional Advice. Journal of Economic Theory $126(1), 120-142$.

Ottaviani, M., Sørensen, P. N., 2006b. Reputational Cheap Talk. Rand Journal of Economics 37 (1), 155-175.

Ottaviani, M., Sørensen, P. N., 2006c. The Strategy of Professional Forecasting. Journal of Financial Economics 81 (2), 441-466.

Park, A., Sabourian, H., 2011. Herding and Contrarian Behavior in Financial Markets. Econometrica 79 (4), 973-1026.

Scharfstein, D. S., Stein, J. C., 1990. Herd Behavior and Investment. American Economic Review 80 (3), 465-79.

Shleifer, A., Vishny, R. W., 1997. The Limits of Arbitrage. Journal of Finance 52 (1), 35-55. 
Tirole, J., 1982. On the Possibility of Speculation under Rational Expectations. Econometrica $50(5), 1163-1181$.

Trueman, B., 1994. Analyst Forecasts and Herding Behavior. Review of Financial Studies 7 (1), $97-124$.

Zeira, J., 1999. Informational Overshooting, Booms, and Crashes. Journal of Monetary Economics 43 (1), 237-257.

Zwiebel, J., 1998. Corporate Conservatism and Relative Compensation. Journal of Political Economy 103 (1), 1-25. 